\title{
Some Like it Smooth, and Some Like it Rough: Untangling Continuous and Jump Components in Measuring, Modeling, and Forecasting Asset Return Volatility"
}

\author{
Torben G. Andersen ${ }^{\mathrm{a}}$, Tim Bollerslev ${ }^{\mathrm{b}}$ and Francis X. Diebold ${ }^{\mathrm{c}}$
}

First Draft: February 2003

This Version: September 2003

\begin{abstract}
A rapidly growing literature has documented important improvements in volatility measurement and forecasting performance through the use of realized volatilities constructed from highfrequency returns coupled with relatively simple reduced-form time series modeling procedures. Building on recent theoretical results from Barndorff-Nielsen and Shephard $(2003 \mathrm{c}, \mathrm{d})$ for related bipower variation measures involving the sum of high-frequency absolute returns, the present paper provides a practical framework for non-parametrically measuring the jump component in realized volatility measurements. Exploiting these ideas for a decade of high-frequency five-minute returns for the DM/\$ exchange rate, the S\&P500 market index, and the 30-year U.S. Treasury bond yield, we find the jump component of the price process to be distinctly less persistent than the continuous sample path component. Explicitly including the jump measure as an additional explanatory variable in an easy-toimplement reduced form model for realized volatility results in highly significant jump coefficient estimates at the daily, weekly and quarterly forecast horizons. As such, our results hold promise for improved financial asset allocation, risk management, and derivatives pricing, by separate modeling, forecasting and pricing of the continuous and jump components of total return variability.
\end{abstract}

Keywords: Continuous-time methods; jumps; quadratic variation; realized volatility; bi-power variation; high-frequency data; volatility forecasting; HAR-RV model.

JEL Codes: C1, G1

Correspondence: Send all correspondence (by email) to F.X. Diebold at fdiebold@sas.upenn.edu.

\footnotetext{
${ }^{*}$ This research was supported by the National Science Foundation, the Guggenheim Foundation, and the Wharton Financial Institutions Center. We are grateful to Olsen and Associates for generously supplying their intraday exchange rate data. We would also like to thank Neil Shephard and George Tauchen for many insightful discussions and comments, as well as seminar participants at the 2003 NBER/NSF Time Series Conference at the University of Chicago.

a Department of Finance, Kellogg School of Management, Northwestern University, Evanston, IL 60208, and NBER, phone: 847-467-1285, e-mail: t-andersen@kellogg.northwestern.edu

${ }^{\mathrm{b}}$ Department of Economics, Duke University, Durham, NC 27708, and NBER, phone: 919-660-1846, e-mail: boller@econ.duke.edu

${ }^{c}$ Department of Economics, University of Pennsylvania, Philadelphia, PA 19104, and NBER, phone: 215-898-1507, e-mail: fdiebold@sas.upenn.edu
}

Copyright (C) 2003 T.G. Andersen, T. Bollerslev and F.X. Diebold 


\section{Introduction}

Volatility is central to asset pricing, asset allocation and risk management. In contrast to the estimation of expected returns, which generally requires long time spans of data, the results in Merton (1980) and Nelson (1992) suggest that volatility may be estimated arbitrarily well through the use of sufficiently finely sampled high-frequency returns over any fixed time interval. However, the assumption of a continuous sample path diffusion underlying these theoretical results is invariably violated in practice at the highest intradaily sampling frequencies. Thus, despite the increased availability of high-frequency data for a host of different financial instruments, practical complications have hampered the implementation of direct high-frequency volatility modeling and filtering procedures (see, e.g., the discussion in Aït-Sahalia and Mykland, 2003; Andersen, Bollerslev and Diebold, 2003; Bai, Russell, and Tiao, 2001; Engle and Russell, 2003).

In response to this situation, Andersen and Bollerslev (1998), Andersen, Bollerslev, Diebold and Labys (2001) (henceforth ABDL), Barndorff-Nielsen and Shephard (2002a,b), and Meddahi (2002), among others, have recently advocated the use of so-called realized volatility measures constructed from the summation of high-frequency intradaily squared returns as a way of conveniently circumventing the data complications, while retaining (most of) the relevant information in the intraday data for measuring, modeling and forecasting volatilities over daily and longer horizons. Indeed, the empirical results in ABDL (2003) suggest that simple reduced form time series models for realized volatility perform as well, if not better, than the most commonly used GARCH and related stochastic volatility models in terms of out-of-sample forecasting. ${ }^{1}$

At the same time, other recent studies have pointed to the importance of explicitly allowing for jumps, or discontinuities, in the estimation of parametric stochastic volatility models as well as in the pricing of options and other derivatives instruments (e.g., Andersen, Benzoni and Lund, 2002; Bates, 2002; Chan and Maheu, 2002; Chernov, Gallant, Ghysels, and Tauchen, 2003; Drost, Nijman and Werker, 1998; Eraker, Johannes and Polson, 2003; Johannes, Kumar and Polson, 1999; Maheu and McCurdy, 2003; Khalaf, Saphores and Bilodeau (2003; and Pan, 2002). In particular, it appears that the conditional variance of many assets is best described by a combination of a smooth and very slowly mean-reverting continuous sample path process, along with a much less persistent jump component.

Set against this backdrop, the present paper seeks to further advance the reduced-form volatility forecasting procedures advocated in ABDL (2003) through the development of a practical non-parametric procedure for separately measuring the continuous sample path variation and the discontinuous jump part of the quadratic variation process. Our approach builds directly on the new theoretical results in

1 These empirical findings have been further corroborated by the theoretical results for specific parametric diffusions in Andersen, Bollerslev and Meddahi (2004). 
Barndorff-Nielsen and Shephard (2003a) involving so-called bi-power variation measures constructed from the summation of appropriately scaled cross-products of adjacent high-frequency absolute returns. ${ }^{2}$ Implementing these ideas empirically with more than a decade long sample of five-minute high-frequency returns for the DM/\$ foreign exchange market, the S\&P500 market index, and the 30-year U.S. Treasury yield, we shed new light on the dynamic dependencies and the relative importance of jumps across the different markets. We also demonstrate important gains in terms of volatility forecast accuracy by explicitly differentiating the jump component. These gains obtain at daily, weekly, and even monthly forecast horizons. Our new forecasting model incorporating the jumps builds directly on the reduced form heterogenous AR model for the realized volatility, or HAR-RV model, due to Müller et al. (1997) and Corsi (2003), in which the realized volatility is parameterized as a linear function of the lagged realized volatilities over different horizons.

The plan for the rest of the paper is as follows. The next section outlines the basic bi-power variation theory of Barndorff-Nielsen and Shephard (2003c,d). Section 3 details the data and highlights the most important qualitative features of the basic jump measurements for each of the three markets. Section 4 describes the HAR-RV volatility model and the resulting gains obtained by explicitly including the jump component as an additional explanatory variable. Section 5 presents a simple statistical procedure for measuring "significant" jumps, and demonstrates that by including the "significant" jumps and the corresponding continuous sample path variability measures as separate explanatory variables in the HAR-RV model further enhances the forecast performance. Section 6 concludes with suggestions for future research.

\section{Theoretical Framework}

Let $p(t)$ denote the time $t$ logarithmic price of the asset. The continuous-time jump diffusion processes traditionally used in asset pricing finance are then most conveniently expressed in stochastic differential equation form as,

$$
d p(t)=\mu(t) d t+\sigma(t) d W(t)+\kappa(t) d q(t), \quad 0 \leq t \leq T
$$

where $\mu(t)$ is a continuous and locally bounded variation process, the stochastic volatility process $\sigma(t)$ is

\footnotetext{
${ }^{2}$ Note that this approach is distinctly different from that of Aït-Sahalia (2002), who relies on estimates of the transition density function for identifying jumps.
} 
strictly positive and càglàd, ${ }^{3} W(t)$ denotes a standard Brownian motion, $d q(t)$ is a counting process with $d q(t)=1$ corresponding to a jump at time $t$ and $d q(t)=0$ otherwise with (possibly time-varying) jump intensity $\lambda(t),{ }^{4}$ and $\kappa(t)$ refers to the size of the corresponding jumps. The quadratic variation (or notional volatility/variance in the terminology of $\mathrm{ABD}, 2003)$ for the cumulative return process, $r(t) \equiv p(t)-p(0)$, is then given by

$$
[r, r]_{t}=\int_{n}^{t} \sigma^{2}(s) d s+\sum_{0<s \leq t} \kappa^{2}(s) .
$$

Of course, in the absence of jumps, the second term on the right-hand-side disappears, and the quadratic variation is simply equal to the integrated volatility.

Several recent studies involving the direct estimation of continuous time stochastic volatility models along the lines of equation (1) (e.g., Andersen, Benzoni and Lund, 2002; Eraker, Johannes and Polson, 2003; Eraker, 2003; Johannes, Kumar and Polson, 1999) have highlighted the importance of explicitly incorporating jumps in the price process. The specific parametric model estimates reported in this literature have also generally found the dynamic dependencies in the jumps to be much less persistent than the dependencies in the continuous sample path volatility process. However, instead of relying on these model-driven procedures for separately identifying the two components in equation (2), we will utilize a new non-parametric and purely data-driven high-frequency approach.

\subsection{High-Frequency Data, Bi-Power Variation, and Jumps}

Let the discretely sampled $\Delta$-period returns be denoted by, $r_{t, \Delta} \equiv p(t)-p(t-\Delta)$. For ease of notation we normalize the daily time interval to unity and label the corresponding discretely sampled daily returns by a single time subscript, $r_{t+1} \equiv r_{t+1,1}$. Also, we define the daily realized volatility by the summation of the corresponding $1 / \Delta$ high-frequency intradaily squared returns,

$$
R V_{t+1}(\Delta) \equiv \sum_{j=1}^{1 / \Delta} r_{t+j \cdot \Delta, \Delta}^{2}
$$

where for notational simplicity and without loss of generality $1 / \Delta$ is assumed to be an integer. Then as

\footnotetext{
${ }^{3}$ Note that this assumption allows for discrete jumps in the stochastic volatility process.

${ }^{4}$ Formally, $P[q(s)=0, t-h<s \leq t]=1-\int_{0}^{h} \lambda(t-h+s) d s+o(h), P[q(s)=1, t-h<s \leq t]=\int_{0}^{h} \lambda(t-h+s) d s+o(h)$, and $P[q(s) \geq 2, t$ $h<s \leq t]=o(h)$.
} 
emphasized in the series of recent papers by Andersen and Bollerslev (1998), ABDL (2001), BarndorffNielsen and Shephard (2002a,b) and Comte and Renault (1998), among others, by the theory of quadratic variation this realized volatility converges uniformly in probability to the increment to the quadratic variation process defined above as the sampling frequency of the underlying returns increases.

Specifically, for $\Delta \rightarrow 0$,

$$
R V_{t+1}(\Delta) \rightarrow \int_{t}^{t+1} \sigma^{2}(s) d s+\sum_{t<s \leq t+1} \kappa^{2}(s)
$$

In the absence of jumps the realized volatility is therefore consistent for the integrated volatility that figures prominently in the stochastic volatility option pricing literature. This result, in part, motivates the reduced-form time series modeling and forecasting procedures for realized volatilities advocated in ABDL (2003). It is clear that in general the realized volatility proxies will inherit the dynamic dependencies in both the integrated volatility, and if present, the jump dynamics. Although this does not impinge upon the theoretical justification for directly modeling and forecasting $R V_{t+I}(\Delta)$ through simple reduced-form time series procedures, it does suggest that even better forecasting models may be constructed by separately measuring and modeling the two components in equation (4). ${ }^{5}$

Set against this backdrop, the present paper seeks to further enhance on the predictive gains demonstrated in ABDL (2003) through the use of new and powerful asymptotic results (for $\Delta \rightarrow 0$ ) in Barndorff-Nielsen and Shephard $(2003 \mathrm{c}, \mathrm{d})$ that allow for separate (non-parametric) identification of the two components of the quadratic variation process. Specifically, on defining the standardized realized $b i$ power variation measure, ${ }^{6}$

${ }^{5}$ General asymptotic results for so-called realized power variation measures have recently been established by BarndorffNielsen and Shephard (2003a,c); see also Barndorff-Nielsen, Graversen and Shephard (2003) for a survey of related results. In particular, it follows that in the presence of jumps and for $0<p<2$ and $\Delta \rightarrow 0$,

$$
R P V_{t+1}(\Delta, p) \equiv \mu_{p}^{-1} \Delta^{1-p / 2} \sum_{j=1}^{1 / \Delta}\left|r_{t+j \cdot \Delta, \Delta}\right|^{p} \rightarrow \int_{t}^{t+1} \sigma^{p}(s) d s,
$$

where $\mu_{p} \equiv 2^{p / 2} \Gamma(1 / 2(p+1)) /(1 / 2)$ denotes to the $p$ th absolute moment of a standard normal random variable. Hence, the impact of the discontinuous jump process disappears in the limit for the power variation measures with $0<p<2$. In contrast, $R P V_{t+1}(\Delta, p)$ diverges to infinity for $p>2$, while $R P V_{t+1}(\Delta, 2) \equiv R V_{t+1}(\Delta)$ converges to the integrated volatility plus the sum of the squared jumps, as in equation (4). Related expressions for the conditional moments of different powers of absolute returns have also been utilized by AïtSahalia (2003) in the formulation of a GMM-type estimator for specific jump-diffusion models.

${ }^{6}$ We shall concentrate on the simplest case involving the summation of adjacent absolute returns, but the general theory developed in Barndorff-Nielsen and Shephard (2003a,c) pertains to other powers and lag lengths as well. 


$$
B V_{t+1}(\Delta) \equiv \mu_{1}^{-2} \sum_{j=2}^{1 / \Delta}\left|r_{t+j \cdot \Delta, \Delta}\right|\left|r_{t+(j-1) \cdot \Delta, \Delta}\right|
$$

where $\mu_{1} \equiv \sqrt{ }(2 / \pi)$, it follows that for $\Delta \rightarrow 0$,

$$
B V_{t+1}(\Delta) \rightarrow \int_{t}^{t+1} \sigma^{2}(s) d s
$$

Hence, as first noted by Barndorff-Nielsen and Shephard (2003c), combining the results in equations (4) and (6), the contribution to the quadratic variation process due to the discontinuities (jumps) in the underlying price process may be consistently estimated by

$$
R V_{t+1}(\Delta)-B V_{t+1}(\Delta) \rightarrow \sum_{t<s \leq t+1} \kappa^{2}(s)
$$

This is the central insight on which the remainder of the empirical and theoretical results in the paper, including the volatility model estimates and forecasts in the next following sections, builds. Of course, nothing prevents the right hand-side of (7) from becoming negative in a given sample. Thus we impose a non-negativity truncation on the actual empirical jump measurements,

$$
J_{t+1}(\Delta) \equiv \max \left[R V_{t+1}(\Delta)-B V_{t+1}(\Delta), 0\right]
$$

following the suggestion of Barndorff-Nielsen and Shephard (2003c).

\section{Data Description, Realized Volatilities, and Jumps}

We present the results for three distinct markets: the $\mathrm{DM} / \$$ foreign exchange market, the aggregate U.S. stock market as summarized by the S\&P500 index, and the fixed income market as represented by the 30 -year U.S. Treasury bond yield. The DM/\$ volatilities cover the period from December 1986 through June 1999, for a total of 3,045 daily observations. The underlying highfrequency spot quotations were kindly provided by Olsen \& Associates in Zurich, Switzerland. This same series has been previously analyzed in the series of papers by $\operatorname{ABDL}(2001,2003)$. The S\&P500 volatility measurements are based on tick-by-tick transactions prices from the Chicago Mercantile Exchange (CME) and cover the period from January 1990 through December 2002, for a total of 3,262 daily observations. The T-bond volatilities are similarly constructed from tick-by-tick transactions prices 
for the 30 year U.S. Treasury Bond futures contract traded on the Chicago Board of Trade (CBOT), and cover the identical January 1990 through December 2002 period. A more detailed description of the S\&P and T-bond data is available in Andersen, Bollerslev, Diebold and Vega (2003b), where the same highfrequency data are analyzed from a very different perspective. All of the volatility measures are based on linearly interpolated logarithmic five-minute returns, as in Müller et al. (1990) and Dacorogna et al. (1993). ${ }^{7}$ For the foreign exchange market this results in a total of $1 / \Delta=288$ high-frequency return observations per day, while the two futures contracts are actively traded for $1 / \Delta=97$ five-minute intervals per day. For notational simplicity, we omit the explicit reference to $\Delta$ in the following, referring to the five-minute realized volatilities and jumps defined by equations (3) and (8) as $R V_{t}$ and $J_{t}$, respectively.

The first panels in Figures 1A-C show the resulting three daily realized volatility series in standard deviation form, or $R V_{t}^{1 / 2}$. Each of the three series clearly exhibits a high degree of own serial correlation. This is confirmed by the Ljung-Box statistic for up to tenth order serial correlation reported in Tables 1A-C equal to 5,714, 12,335, and 1,677, respectively. Similar results obtain for the realized variances and logarithmic transformations reported in the first and third columns in the tables.

Comparing the volatility across the three markets, the S\&P500 returns are the most volatile, followed by the exchange rate returns. Also, consistent with the earlier evidence for the foreign exchange market in ABDL (2001), and the related findings for individual stocks in Andersen, Bollerslev, Diebold and Ebens (2002) and for the S\&P500 in Deo, Hurvich and Lu (2003) and Martens, van Dijk and Pooter (2003), the logarithmic standard deviations are generally much closer to being normally distributed than are the raw realized volatility series. Hence, from a modeling perspective, the logarithmic realized volatilities are more amenable to the use of standard time series procedures. ${ }^{8}$

Of course, all of the realized volatility series include the continuous sample path variability as well as the contribution coming from the jump component. The second panels in Figures 1A-C display the separate measurements of the jump components (again in standard deviation form) based on the truncated estimator in equation (8). As is evident from the figures, many of the largest realized volatilities are directly associated with jumps in the underlying price process. There is also a tendency for

\footnotetext{
${ }^{7}$ A number of recent studies have investigated the practical choice of $\Delta$ together with different filtering procedures in order to best mitigate the impact of market microstructure effects in the construction of realized volatility measures (e.g., ABDL, 2000; Aït-Sahalia and Mykland, 2003; Andreou and Ghysels, 2002; Areal and Taylor, 2002; Bai, Russell and Tiao, 2001; Bandi and Russell, 2003; Barruci and Reno, 2002; Bollen and Inder, 2002; Corsi, Zumbach, Müller and Dacorogna, 2001; Curci and Corsi, 2003; and Martens, 2003). For ease of implementation, we simply follow ABDL $(2002,2001)$ in the use of unweighted five-minute returns for each of the three active markets analyzed here.

${ }^{8}$ Modeling and forecasting $\log$ volatility also has the virtue of automatically imposing non-negativity of fitted and forecasted volatilities.
} 
the largest jumps in the $\mathrm{DM} / \$$ market to cluster during the earlier 1986-88 part of the sample, while the size of the jumps for the S\&P500 has increased significantly over the most recent 2001-02 two-year period. In contrast, the jumps in the T-Bond market appear to be distributed more homogeneously throughout the sample.

These visual observations are readily confirmed by the Ljung-Box portmanteau statistics for up to tenth order serial correlation in the $J_{t}, J_{t}^{1 / 2}$, and $\log \left(J_{t}+1\right)$ series reported in the last three columns in Tables 1A-C. It is noteworthy, however, that although the Ljung-Box statistics for the jumps are significant at conventional significance levels, the actual values are markedly lower than the corresponding test statistics for the realized volatility series reported in the first three columns. This indicates decidedly less predictability in the part of the quadratic variation originating from the discontinuous sample path part of the process compared to the continuous sample path variation. The numbers in the table also show that the jumps are relatively least important for the DM $/ \$$ market, with the mean of $J_{t}$ accounting for 0.072 of the mean of $R V_{t}$, while the same ratios for the S\&P500 and T-bond markets are 0.146 and 0.125 , respectively. ${ }^{9}$

Motivated by these empirical observations, we now put the idea of separately measuring the jump component to work in the construction of new and improved realized volatility models and corresponding forecasts. We follow ABDL (2003) in directly estimating a set of simple reduced-form time series models for each of the different realized volatility measures in Tables $1 \mathrm{~A}-\mathrm{C}$; i.e., $R V_{t}, R V_{t}^{1 / 2}$, and $\log \left(R V_{t}\right.$ ). Then, in order to assess the added value of separately measuring the jump component in forecasting the realized volatilities, we simply include the $J_{t}, J_{t}^{1 / 2}$, and $\log \left(J_{t}+1\right)$ jump measurements as additional explanatory variables in the various forecasting regressions.

\section{Reduced-Form Realized Volatility Modeling and Forecasting}

A number of empirical studies have argued for the existence of long-memory dependencies in financial market volatility, and several different parametric $\mathrm{ARCH}$ and stochastic volatility formulations have been proposed in the literature for capturing this phenomenon (e.g., Andersen and Bollerslev, 1997a; Baillie, Bollerslev, and Mikkelsen, 1996; Breidt, Crato and de Lima, 1998; Dacorogna et al., 2001; Ding, Granger and Engle, 1993; Robinson, 1991). These same empirical observations have also motivated the estimation of long-memory type ARFIMA models for realized volatility in ABDL (2003), Areal and Taylor (2002), Deo, Hurvich and Lu (2003), Hol and Koopman (2002), Martens, van Dijk, and Pooter (2003), Pong, Shackleton, Taylor and Xu (2003), Thomakos and Wang (2003), among others.

\footnotetext{
9 The corresponding ratios for the mean of $J_{t}^{1 / 2}$ relative to the mean $R V_{t}^{1 / 2}$ are $0.193,0.251$, and 0.289 for each of the three markets, respectively.
} 
Instead of these relatively complicated estimation procedure, we will here rely on the simple HAR-RV class of volatility models recently proposed by Corsi (2003). This model is based on a straightforward extension of the so-called Heterogeneous ARCH, or $\mathrm{HARCH}$, class of models first introduced by Müller et al. (1997), which parameterizes the conditional variance for a given return horizon as a function of the lagged squared return over the same and other horizons. ${ }^{10}$ Although this model doesn't formally possess long-memory, the mixing of relatively few volatility components is able to reproduce a very slow decay that is almost indistinguishable from that of a hyperbolic pattern over shorter empirically relevant forecast horizons. ${ }^{11}$

\subsection{The HAR-RV-J Model}

To sketch the HAR-RV model, define the multi-period realized volatilities by the normalized sum of the one-period volatilities,

$$
R V_{t, t+h}=h^{-1}\left[R V_{t+1}+R V_{t+2}+\ldots+R V_{t+h}\right]
$$

Note that, by definition of the daily volatilities, $R V_{t, t+1} \equiv R V_{t+1}$. Also, provided the expectations exist, $E\left(R V_{t, t+h}\right) \equiv E\left(R V_{t+1}\right)$ for all $h$. Nonetheless, for ease of reference, we will refer to these normalized volatility measures for $h=5$ and $h=22$ as the weekly and monthly volatilities, respectively. The daily HAR-RV model of Corsi (2003) may then be expressed as

$$
R V_{t+1}=\beta_{0}+\beta_{D} R V_{t}+\beta_{W} R V_{t-5, t}+\beta_{M} R V_{t-22, t}+\epsilon_{t+1} .
$$

Of course, realized volatilities over other horizons could easily be included as explanatory variables, but the daily, weekly and monthly measures employed here afford a natural economic interpretation. ${ }^{12}$

This HAR-RV forecasting model for the one-day volatilities extends straightforwardly to models

\footnotetext{
${ }^{10}$ Müller et al. (1997) heuristically motivates the HARCH model through the existence of distinct group of traders with different investment horizons.

11 See also the discussion of the use of low-order ARMA models in approximating and forecasting long-memory type behavior in the conditional mean in Basak, Chan and Palma (2001), Cox (1991), Hsu and Breidt (2003), Man (2003), O'Connell (1971) and Tiao and Tsay (1994), among others, along with the discussion of the related component GARCH model in Engle and Lee (1999), the corresponding multi-factor continuous time stochastic volatility model in Gallant, Hsu and Tauchen (1999), and the related multifractal regime switching models in Calvet and Fisher $(2001,2002)$.

12 A closely related set of mixed data sampling, or MIDAS, regressions have recently been analyzed and estimated empirically by Ghysels, Santa-Clara and Valkanov (2002).
} 
for the realized volatilities over other horizons, $R V_{t, t+h}$. Moreover, given the separate measurements of the jump components discussed above, these are readily included as additional explanatory variables over and above the longer-run realized volatility components, resulting in the new HAR-RV-J model,

$$
R V_{t, t+h}=\beta_{0}+\beta_{D} R V_{t}+\beta_{W} R V_{t-5, t}+\beta_{M} R V_{t-22, t}+\beta_{J} J_{t}+\epsilon_{t, t+h}
$$

With single-period observations and longer forecast horizons, or $h>1$, the error term will generally be serially correlated up to at least order $h-1$ due to a standard overlapping data problem. We correct for this in the standard errors reported below through the use of a Bartlett/Newey-West heteroskedasticity consistent covariance matrix estimator with 5, 10, and 44 lags for the daily $(h=1)$, weekly $(h=5)$, and monthly $(h=22)$ estimates, respectively.

Turning to the results reported in the first three columns in Tables $2 \mathrm{~A}-\mathrm{C}$, the estimates for $\beta_{D}, \beta_{W}$, and $\beta_{M}$ confirm the existence of highly persistent dependencies in the volatilities. Interestingly, the relative importance of the daily volatility component decreases from the daily to the weekly to the monthly forecasts, whereas the monthly volatility component tends to be relatively more important for the longer-run monthly forecasts. Importantly, the estimates for the jump component, $\beta_{J}$, are systematically negative across all models and markets, and with few exceptions, overwhelmingly significant. Thus, whereas the realized volatilities are generally highly persistent, the impact of the lagged realized volatility is significantly reduced on days in which the jump component is active. For instance, for the daily DM/\$ realized volatility a unit increase in the daily realized volatility implies an average increase in the volatility on the following day of $0.430+0.196 / 5+0.244 / 22=0.480$ for days without any jumps, whereas for days in which part of the realized volatility comes from the jump component the increase in the volatility on the following day is reduced by -0.486 times the jump component. In other words, if the realized volatility is entirely attributable to jumps, it carries no predictive power for the following day's realized volatility. Similarly for the other two markets, the combined impact of a jump for forecasting the next day's realized volatility equal $0.317+0.499 / 5+0.165 / 22-0.436=-0.012$ and $0.069+0.316 / 5+$ $0.360 / 22-0.151=-0.002$, respectively. These results are entirely consistent with the parameter estimates for specific stochastic volatility jump-diffusion models reported in the recent literature, which as previously noted suggest very little, or no, predictable variation in the jump process.

Comparing the $R^{2}$ 's for the HAR-RV-J models to the $R^{2}$ 's for the "standard" HAR model reported in the last row in which the jump component is absent and the realized volatilities on the righthand-side but not the left-hand-side of equation (11) are replaced by the corresponding lagged squared daily, weekly, and monthly returns clearly highlights the added value of high-frequency data in volatility 
forecasting. Although the coefficient estimates for the $\beta_{D}, \beta_{W}$, and $\beta_{M}$ coefficients in the "standard" HAR models (available upon request) generally are very close to those of the HAR-RV-J models reported in the tables, the explained variation is systematically much lower. ${ }^{13}$ Importantly, the gains afforded by the use of realized volatilities constructed from high-frequency data are not restricted to the daily and weekly horizons. In fact, the longer-run monthly forecasts result in the largest relative increases in $R^{2}$, s, with those for the S\&P500 and U.S. T-Bonds tripling for the HAR-RV-J models relative to those from the HAR models based on the coarser daily, weekly and monthly squared returns. These large gains in forecast accuracy through the use of realized volatilities based on high-frequency data are, of course, entirely consistent with the earlier empirical evidence for the foreign exchange market in ABDL (2003) and Bollerslev and Wright (2002), as well as the theoretical calculations in Andersen, Bollerslev and Meddahi (2004).

\subsection{Standard Deviation and Logarithmic HAR-RV-J Models}

Practical uses of volatility often center on forecasts of standard deviations as opposed to variances. The second row in each of Tables 1-3 reports the parameter estimates and $R^{2}$, s for the corresponding HAR-RV-J model cast in the form of standard deviations,

$$
\left(R V_{t, t+h}\right)^{1 / 2}=\beta_{0}+\beta_{D} R V_{t}^{1 / 2}+\beta_{W}\left(R V_{t-5, t^{1 / 2}}+\beta_{M}\left(R V_{t-22, t^{1 / 2}}+\beta_{J} J_{t}^{1 / 2}+\epsilon_{t, t+h} .\right.\right.
$$

The qualitative features and ordering of the different parameter estimates are generally the same as for the variance formulation in equation (11). In particular, the estimates for $\beta_{J}$ are systematically negative. Similarly, the $R^{2}$ 's indicate quite dramatic gains for the high-frequency based HAR-RV-J model relative to the standard HAR model. The more robust volatility measurements provided by the standard deviations also result in higher $R^{2}$, $\mathrm{s}$ than for the variance-based models reported in the first three columns. ${ }^{14}$

To further illustrate the predictability afforded by the HAR-RV-J model in equation (12), we plot in Figures 2A-C the daily, weekly, and monthly realized volatilities (again in standard deviation form)

\footnotetext{
${ }^{13}$ Note that although the relative magnitude of the $R^{2}$, s for a given volatility series are directly comparable across the two models, as discussed in Andersen, Bollerslev and Meddahi (2002), the measurement errors in the left-hand-side realized volatility measures result in a systematic downward bias in the values of the reported $R^{2}$, s relative to the predictability of true latent quadratic variation process.

14 The $R^{2}=0.431$ for the daily HAR-RV-J model for the DM/ $\$$ realized volatility series in the fourth column in Table $2 \mathrm{~A}$ also exceeds the comparable in-sample one-day-ahead $R^{2}=0.355$ for the long-memory VAR model reported in ABDL (2003).
} 
together with the corresponding forecasts. The close coherence between the different pairs of realizations and forecasts is immediately evident across all of the graphs. Visual inspection of the graphs also confirms that the U.S. T-Bond volatility is the least predictable of the three markets, followed by the $\mathrm{DM} / \$$, and then the S\&P500. Nonetheless, the forecasts for the T-Bond volatilities still track the overall patterns fairly well, especially at the weekly and monthly horizons. The marked increase in equity market volatility starting in the late 90's is also directly visible in each of the three panels in Figure 2B.

As noted in Table 1 above, the logarithmic daily realized volatilities are approximately unconditionally normally distributed for each of the three markets. This empirical regularity motivated ABDL (2003) to model the logarithmic realized volatilities, in order to invoke the use of standard normal distribution theory and related mixture models, and this same transformation has subsequently been used successfully for other markets by Deo, Hurvich and Lu (2003), Holl and Koopman (2002), and Martens, van Dijk and Pooter (2003), among others. ${ }^{15}$ Guided by this same idea, we report in the last three columns of Tables 2A-C the estimates for the HAR-RV-J model cast in logarithmic form as

$\log \left(R V_{t, t+h}\right)=\beta_{0}+\beta_{D} \log \left(R V_{t}\right)+\beta_{W} \log \left(R V_{t, t-5}\right)+\beta_{M} \log \left(R V_{t, t-22}\right)+\beta_{J} \log \left(J_{t}+1\right)+\epsilon_{t, t+h}$.

The estimates are directly in line with those for the HAR-RV-J models for $R V_{t, t+h}$ and $\left(R V_{t, t+h}\right)^{1 / 2}$ discussed previously. In particular, the $\beta_{D}$ coefficients are generally the largest in the daily models, the $\beta_{W}$ 's are the most important in the weekly models, and the $\beta_{M}$ 's in the monthly models. At the same time, the "new" estimates for the $\beta_{J}$ coefficients imply that the most significant discontinuities, or jumps, in the price processes are typically associated with very short-lived bursts in volatility. As previously noted, these results are generally consistent with the findings in the extant empirical literature on multi-factor jumpdiffusion models. However, the new jump measurements and reduced-form HAR-RV-J models developed here afford a particularly simple and easy-to-implement modeling procedure for effectively incorporating these features into more accurate financial market volatility forecasts.

\section{Significant Jumps}

The empirical results discussed in the previous two sections rely on the simple non-parametric jump estimates defined by the difference between the realized volatility and the bi-power variation. As

15 Of course, if the daily realized volatilities are normally distributed, the weekly and monthly volatilities can not also be normally distributed. However, as argued by Barndorff-Nielsen and Shephard (2002a) and Forsberg and Bollerslev (2002) within the context of volatility modeling, the log-normal distribution is closely approximated by the Inverse Gaussian distribution, the later of which is formally closed under temporal aggregation. 
discussed in Section 2, the theoretical justification for these measurements is based on the notion of increasingly more finely sampled returns, or $\Delta \rightarrow 0$. Of course, any practical implementation with a fixed sampling frequency, or $\Delta>0$, is invariably subject to measurement errors. The non-negativity truncation in equation (8) alleviates part of this finite-sample problem by eliminating theoretically non-sensible negative estimates for the squared jumps. However, the resulting $J_{t}^{1 / 2}$ series depicted in Figures $1 \mathrm{~A}-\mathrm{C}$ arguably exhibit an unreasonably large number of non-zero small positive values as well. From a structural modeling perspective it may be desirable to treat these small jumps, or measurement errors, as part of the continuous sample path variation process, only associating abnormally large values of $R V_{t}(\Delta)$ $B V_{t}(\Delta)$ with the jump component. The following section provides a theoretical framework for doing so.

\subsection{Theoretical Framework}

The distributional results in Barndorff-Nielsen and Shephard $(2003 \mathrm{c}, \mathrm{d})$ imply that in the absence of jumps and for $\Delta \rightarrow 0$,

$$
\frac{R V_{t+1}(\Delta)-B V_{t+1}(\Delta)}{\left[\left(\mu_{1}^{-4}+2 \mu_{1}^{-2}-5\right) \Delta \int_{t}^{t+1} \sigma^{4}(s) d s\right]^{1 / 2}} \Rightarrow N(0,1) .
$$

Hence, an abnormally large value of this standardized difference between $R V_{t+1}(\Delta)$ and $B V_{t+I}(\Delta)$ is naturally interpreted as evidence in favor of a "significant" jump over the $[t, t+1]$ time interval. Of course, the integrated quarticity that appears in the denominator needs to be estimated in order to actually implement this statistic. In parallel to the arguments underlying the robust estimation of the integrated volatility by the realized bi-power variation it is possible to show that even in the presence of jumps the integrated quarticity may be consistently estimated by the normalized sum of the product of $n \geq 3$ adjacent absolute returns raised to the power of $4 / n$. In particular, on defining the standardized realized tri-power quarticity measure,

$$
T Q_{t+1}(\Delta) \equiv \Delta^{-1} \mu_{4 / 3}^{-3} \sum_{j=3}^{1 / \Delta}\left|r_{t+j \cdot \Delta, \Delta}\right|^{4 / 3}\left|r_{t+(j-1) \cdot \Delta, \Delta}\right|^{4 / 3}\left|r_{t+(j-2) \cdot \Delta, \Delta}\right|^{4 / 3}
$$

where $\mu_{4 / 3} \equiv 2^{2 / 3} \cdot \Gamma(7 / 6) \cdot \Gamma(1 / 2)^{-1}$, it follows that for $\Delta \rightarrow 0$, 


$$
T Q_{t+1}(\Delta) \Rightarrow \int_{t}^{t+1} \sigma^{4}(s) d s
$$

Combining the results in equations (14)-(16), the "significant" jumps may therefore be identified by examining the feasible test statistics, ${ }^{16}$

$$
W_{t+1}(\Delta) \equiv \frac{R V_{t+1}(\Delta)-B V_{t+1}(\Delta)}{\left[\Delta\left(\mu_{1}^{-4}+2 \mu_{1}^{-2}-5\right) T Q_{t+1}(\Delta)\right]^{1 / 2}},
$$

relative to a standard normal distribution.

Recent simulation-based evidence for various continuous time diffusion models in Huang and Tauchen (2003), suggests that the $W_{t+l}(\Delta)$ statistic defined in (17) tends to over-reject the null hypothesis of no jumps in the far right tail of the distribution. Hence, following the approach advocated by Barndorff-Nielsen and Shephard (2003b) and Huang and Tauchen (2003) for improving the finite sample behavior of the standardized realized volatility distribution, we rely on a log-based version of the test statistic in (17). Specifically, on applying the delta-rule to the joint bivariate distribution of the realized volatility and the bi-power variation it follows that the log-transformed test statistic,

$$
Z_{t+1}(\Delta) \equiv \frac{\log \left(R V_{t+1}(\Delta)\right)-\log \left(B V_{t+1}(\Delta)\right)}{\left[\Delta\left(\mu_{1}^{-4}+2 \mu_{1}^{-2}-5\right) T Q_{t+1}(\Delta) B V_{t+1}(\Delta)^{-2}\right]^{1 / 2}},
$$

should also be asymptotically normally distributed in the absence of jumps (see also Barndorff-Nielsen and Shephard, 2003c,d). Importantly, however, the simulation results in Huang and Tauchen (2003) show that $Z_{t+1}(\Delta)$ is generally much better approximated by a normal distribution in the tails than $\mathrm{W}_{t+1}(\Delta)$.

\footnotetext{
16 Similar results were obtained by using the robust realized quad-power quarticity measure advocated in BarndorffNielsen and Shephard $(2003 \mathrm{c}, \mathrm{d})$,$$
Q Q_{t+1}(\Delta) \equiv \Delta^{-1} \mu_{1}^{-4} \sum_{j=4}^{1 / \Delta}\left|r_{t+j \cdot \Delta, \Delta}\right|\left|r_{t+(j-1) \cdot \Delta, \Delta}\right|\left|r_{t+(j-2) \cdot \Delta, \Delta}\right|\left|r_{t+(j-3) \cdot \Delta, \Delta}\right|
$$

Note however, that the realized quarticity,

$$
R Q_{t+1}(\Delta) \equiv R P V_{t+1}(\Delta, 4) \equiv \Delta^{-1} \mu_{4}^{-1} \sum_{j=1}^{1 / \Delta} r_{t+j \cdot \Delta, \Delta}^{4}
$$

used in estimating the integrated quarticity by Barndorff-Nielsen and Shephard (2002a) and Andersen, Bollerslev, and Meddahi (2002) is not consistent in the presence of jumps, in turn resulting in a complete loss of power for the corresponding test statistic obtained by replacing $T Q_{t+1}(\Delta)$ in equation (17) with $R Q_{t+1}(\Delta)$. 
Hence, in the following we identify the "significant" jumps by the realizations of $Z_{t+1}(\Delta)$ in excess of some critical value, $\Phi_{\alpha}$,

$$
J_{t+1, \alpha}(\Delta) \equiv I\left[Z_{t+1}(\Delta)>\Phi_{\alpha}\right] \cdot\left[R V_{t+1}(\Delta)-B V_{t+1}(\Delta)\right]
$$

where $I[\cdot]$ denotes the indicator function. ${ }^{17}$ Moreover, in order to ensure that the measurements of the continuous sample path variation and the jump component add up to the realized volatility, the former component is naturally estimated by the residual relationship,

$$
C_{t+1, \alpha}(\Delta) \equiv I\left[Z_{t+1}(\Delta) \leq \Phi_{\alpha}\right] \cdot R V_{t+1}(\Delta)+I\left[Z_{t+1}(\Delta)>\Phi_{\alpha}\right] \cdot B V_{t+1}(\Delta)
$$

Note that for $\Phi_{\alpha}>0$, the definitions in equations (19) and (20) automatically guarantee that both $J_{t+l, \alpha}(\Delta)$ and $C_{t+1, \alpha}(\Delta)$ are positive. Hence by formally specifying $\alpha(\Delta) \rightarrow 1$ for $\Delta \rightarrow 0$, this approach affords period-by-period consistent (as $\Delta \rightarrow 0$ ) estimates of the jump variation and the integrated variance, as well as the overall quadratic variation process.

In the following, we again omit the explicit reference to the underlying sampling frequency, $\Delta$, referring to the "significant" jump and continuous sample path variability measures based on the fiveminute returns as $J_{t, \alpha}$ and $C_{t, \alpha}$, respectively. Of course, the non-negativity truncation imposed in equation (8) underlying the empirical jump measurements employed in the preceding two sections simply corresponds to $\alpha=0.5$, or $J_{t} \equiv J_{t, 0.5}$. The next section explores the features of the jump measurements obtained for other values of $\alpha$ ranging from 0.5 to 0.9999 , or $\Phi_{\alpha}$ ranging from 0.0 to 3.719 .

\subsection{Significant Jump Measurements}

The first rows in Tables 3A-C report the proportion of days with significant jumps in each of the three markets. Although the use of $\alpha$ 's in excess of 0.5 has the intended effect of reducing the number of days with significant jumps, the procedure still identifies many more jumps than would be expected if the underlying price process was continuous. ${ }^{18}$ For instance, employing a cutoff of $\alpha=0.999$, or $\Phi_{\alpha}=3.090$, results in 177,267 , and 385 significant jumps for each of the three markets respectively, all of which far

\footnotetext{
17 As noted in personal communication with Neil Shephard, this may alternatively be interpreted as a shrinkage type estimator for the jump component.

18 Barndorff-Nielsen and Shephard (2003d) suggest that jumps in foreign exchange markets are linked to the arrival of macroeconomic news, in accord with the results of Andersen, Bollerslev, Diebold and Vega (2003a).
} 
exceed the expected three jumps for a continuous price process $(0.001$ times 3,045 and 3,262, respectively). These daily jump proportions are much higher than the jump intensities typically estimated with specific parametric jump diffusion models applied to daily or coarser frequency returns. This suggests that many of the jumps identified by the high-frequency based realized volatility measures employed here may be blurred in the coarser daily or lower frequency returns through an aliasing type phenomenon. It is also noteworthy that although the proportions of jumps are somewhat sensitive to the particular choice of $\alpha$, the sample means of the resulting jump series reported in the second set of rows depend less on the significance level.

Comparing the jump intensities across the three markets, the T-Bond market generally exhibits the highest number of jumps, whereas the foreign exchange market has the least. This is consistent with empirical evidence documenting that the fixed income market is generally the most responsive to macroeconomic news announcements (e.g., Andersen, Bollerslev, Diebold and Vega, 2003b). Along these lines, it would be interesting, but beyond the scope of the present paper, to directly associate the significant jumps identified here with specific news arrivals, including regularly-scheduled macroeconomic news releases.

The Ljung-Box statistics for up to tenth order serial correlation in the $J_{t, \alpha}$ series reported in the fourth rows indicate highly significant temporal dependencies in the S\&P500 jump series for all values of $\alpha$. Interestingly, the corresponding test statistics for the $\mathrm{DM} / \$$ and U.S. T-Bond jump series are not nearly as large, and generally insignificant for the jumps defined by $\alpha$ 's in excess of 0.950 . In contrast, the tests for serial correlation in the occurrences of jumps, as measured by the Ljung-Box statistics for the zero-one jump indicator series reported in the fifth set of rows in Tables 3A-C, indicate significant predictability in the jump intensities for all three markets. These results are at odds with most of the parametric jump diffusion models hitherto employed in the literature, which typically assume timeinvariant jump intensities. ${ }^{19}$ Again, it would be interesting, but beyond the scope of the present paper, to explore more fully the nature of these dependencies in the jump process. Some preliminary results along these lines suggest that for the S\&P500, the larger the jumps the more likely it is for jumps to occur in the future; i.e., $J_{t, \alpha}$ and $J_{t+1, \alpha}>0$ are positively correlated. Meanwhile, our estimates for the T-Bond market suggest an anomalous negative relationship between the strength of the diffusive, or continuous sample path, variability, $C_{t, \alpha}$, and the future jump intensity, $J_{t+l, \alpha}>0$. It is worth cautioning, however, that although statistically significant, these correlations typically explain less than one-percent of the variability in the zero-one jump indicator series.

\footnotetext{
19 The recent parametric model estimates reported in Chan and Maheu (2002) and McCurdy and Maheu (2003) also indicate significant time-varying jump intensities in U.S. equity index returns.
} 
The main qualitative features discussed above are underscored by the time series plots for the significant jump series based on $\alpha=0.999$ (again in standard deviation form) depicted in the bottom three panels in Figures 1A-C. The significance tests clearly reduce the number of jumps relative to the $J_{t}^{1 / 2}$ series in the middle set of panels by effectively eliminating most of the smallest jump measures close to zero. To further illustrate the advantage of this procedure, we next turn to a simple extension of the HAR-RV-J model discussed in Section 4 in which we incorporate only the significant jumps.

\subsection{The HAR-RV-CJ Model}

The regression estimates for the HAR-RV-J model in Section 4 show that the inclusion of the simple consistent daily jump measure as an additional explanatory variable over-and-above the daily realized volatilities result in highly significant and negative parameter estimations for the jump coefficient. These results are, of course, entirely consistent with the summary statistics for the jump measurements discussed above, which indicate markedly less own serial correlation in the significant jump series in comparison to the realized volatility series. Building on these results, the present section extends the HAR-RV-J model by explicitly decomposing the realized volatilities that appear as explanatory variables into the continuous sample path variability and the jump variation utilizing the separate non-parametric measurements in equations (19) and (20), respectively. In so doing, we rely on $\alpha$ $=0.999$, corresponding to the jump series depicted in the bottom panels of Figures $1 \mathrm{~A}-\mathrm{C} .{ }^{20}$ However, to facilitate the exposition, we omit the 0.999 subscript on the $J_{t, 0.999}$ and $C_{t, 0.999}$ series in what follows.

In particular, on defining the normalized multi-period jump and continuous sample path variability measures,

$$
J_{t, t+h}=h^{-1}\left[J_{t+1}+J_{t+2}+\ldots+J_{t+h}\right]
$$

and,

$$
C_{t, t+h}=h^{-1}\left[C_{t+1}+C_{t+2}+\ldots+C_{t+h}\right]
$$

respectively, the HAR-RV-CJ model may be expressed as

$$
\begin{aligned}
R V_{t, t+h}=\beta_{0}+ & \beta_{C D} C_{t}+\beta_{C W} C_{t-5, t}+\beta_{C M} C_{t-22, t}+ \\
& +\beta_{J D} J_{t}+\beta_{J W} J_{t-5, t}+\beta_{J M} J_{t-22, t}+\epsilon_{t, t+h} .
\end{aligned}
$$

\footnotetext{
${ }^{20}$ By "optimally" choosing $\alpha$, it may be possible to further improve upon the empirical results reported below. However, for simplicity and to guard against obvious data snooping biases, we simply restrict $\alpha=0.999$. 
The model obviously nests the HAR-RV-J model in (11) for $\beta_{D}=\beta_{C D}+\beta_{J D}, \beta_{W}=\beta_{C W}+\beta_{J W}, \beta_{M}=\beta_{C M}+\beta_{J M}$, and $\beta_{J}=\beta_{J D}$, but otherwise allows for more general dynamic dependencies. ${ }^{21}$

Turning to the empirical estimates in the first three columns in Tables 4A-C, most of the coefficient estimates for the jump components are insignificant. In other words, the predictability in the HAR-RV realized volatility regressions are almost exclusively due to the continuous sample path components. It is also noteworthy that the HAR-RV-CJ models typically result in an increase in the $R^{2}$ of about 0.01 in an absolute sense, or about 2-3 percent relatively, compared to the HAR-RV-J models in Tables 2A-C.

These same qualitative results carry over to the HAR-RV-CJ models cast in standard deviation form,

$$
\begin{aligned}
\left(R V_{t, t+h}\right)^{1 / 2}= & \beta_{0}+\beta_{C D} C_{t}^{1 / 2}+\beta_{C W}\left(C_{t-5, t}\right)^{1 / 2}+\beta_{C M}\left(C_{t-22, t}\right)^{1 / 2} \\
& +\beta_{J D} J_{t}^{1 / 2}+\beta_{J W}\left(J_{t-5, t}\right)^{1 / 2}+\beta_{J M}\left(J_{t-22, t}\right)^{1 / 2}+\epsilon_{t, t+h},
\end{aligned}
$$

and logarithmic form,

$$
\begin{aligned}
\log \left(R V_{t, t+h}\right)= & \beta_{0}+\beta_{C D} \log \left(C_{t}\right)+\beta_{C W} \log \left(C_{t-5, t}\right)+\beta_{C M} \log \left(C_{t-22, t}\right) \\
& +\beta_{J D} \log \left(J_{t}+1\right)+\beta_{J W} \log \left(J_{t-5, t}+1\right)+\beta_{J M} \log \left(C_{t-22, t}+1\right)+\epsilon_{t, t+h} .
\end{aligned}
$$

The coefficient estimates for the jump components, reported in the last set of columns in Tables 4A-C, are again insignificant for most of the different markets and horizons. In contrast, the estimates of $\beta_{C D}, \beta_{C W}$ and $\beta_{C M}$, which quantify the impact of the continuous sample path variability measures, are generally highly significant.

All told, these results further underscore the potential benefit from a volatility forecasting perspective of separately measuring the individual components of the realized volatility. It is possible that even further improvements may be obtained by a more structured approach (in the sense of unobserved-components modeling) in which the jump component, $J_{t}$, and the continuous sample path component, $C_{t}$, are each modeled separately. ${ }^{22}$ These individual models for $J_{t}$ and $C_{t}$ could then be used

21 For the two models to be nested the (implicit) choice of $\alpha$ employed in the measurements of $J_{t, t+h}$ and $C_{t, t+h}$ should, of course, also be the same across models.

22 The results presented here suggest that the jump component is naturally modeled by a discrete mixture model in which the probability of a jump depends non-trivially on past occurrences of jumps, while conditionally on a jump occurring the actual size of the jump may depend non-trivially on the time $t$ information set for some but not all markets. Similarly, the empirical evidence 
in the construction of separate out-of-sample forecasts for each of the components, as well as combined forecasts for the total realized volatility process, $R V_{t, t+h}=C_{t, t+h}+J_{t, t+h}$. We leave further work along these lines for future research.

\section{Concluding Remarks}

Building on the recent theoretical results for bi-power variation measures in Barndorff-Nielsen and Shephard $(2003 \mathrm{c}, \mathrm{d})$, this paper provides a simple practical framework for measuring "significant" jumps. Applying the idea with more than a decade long sample of high-frequency returns from the foreign exchange, equity, and fixed income markets, our methods work well empirically. Consistent with recent parametric estimation results reported in the literature, our measurements of the jump component are much less persistent (and predictable) than the continuous sample path, or integrated volatility, component of the quadratic variation process. Using estimates based on underlying high-frequency data, we identify many more non-zero jumps than do the parametric model estimates based on daily or coarser data reported in the existing literature. Importantly, our results also indicate significant improvements in volatility forecasting from separately including the jump measurements as additional explanatory variables for the future realized volatilities. In fact, when the non-parametric continuous sample path and jump variability measures are included individually in the same forecasting model, only the former measures carry any predictive power for the future realized volatilities.

The ideas and empirical results presented here are suggestive of several interesting extensions. First, recent empirical evidence suggests that jump risk may be priced differently from easier-to-hedge continuous price variability. Hence, separately modeling and forecasting the continuous sample path, or integrated volatility, component and the jump component of the quadratic variation process, may result in more accurate derivatives prices. Second, the high-frequency measures employed here are invariably subject to various market microstructure biases. Thus, it would be interesting to further investigate the "optimal" choice of sampling frequency to employ in the construction of the different variation measures. Along these same lines, it is possible that the procedures for measuring jumps might be improved by offsetting the absolute returns in the realized bi-power and tri-power variation measures by more than one period, in turn circumventing some of the market microstructure biases. Third, in addition to the bipower variation measures investigated here, the use of more standard power variation measures involving the sum of properly normalized absolute returns to powers less than two might afford additional gains in terms of forecast accuracy. Fourth, casual empirical observations suggest that the jumps in the price

discussed above, along with existing reduced form models for the realized volatility (e.g., Forsberg and Bollerslev, 2002), suggests that a Gaussian time series model for $\log \left(C_{t}\right)$ should fit the data for most markets fairly well. 
processes often occur simultaneously across different markets. Hence, it would be interesting to extend the present analysis to a multivariate framework incorporating such commonalities through the use of quadratic covariation and appropriately defined new co-power variation measures. This might also help in better identifying the most important, or significant, jumps in turn resulting in even larger gains in forecast accuracy. 


\section{References}

Ait-Sahalia, Y. (2002), “Telling from Discrete Data Whether the Underlying Continuous-Time Model is a Diffusion," Journal of Finance, 57, 2075-2121.

Aït-Sahalia, Y. (2003), “Disentangling Volatility from Jumps,” Manuscript, Princeton University.

Aït-Sahalia, Y. and P.A. Mykland (2003), "How Often to Sample a Continuous-Time Process in the Presence of Market Microstructure Noise," Manuscript, Princeton University.

Alizadeh, S., M.W. Brandt and F.X. Diebold (2002), "Range-Based Estimation of Stochastic Volatility Models," Journal of Finance, 57, 1047-1091.

Andersen, T.G., L. Benzoni and J. Lund (2002), "Estimating Jump-Diffusions for Equity Returns," Journal of Finance, 57, 1239-1284.

Andersen, T.G. and T. Bollerslev (1997a), "Heterogeneous Information Arrivals and Return Volatility Dynamics: Uncovering the Long-Run in High-Frequency Returns," Journal of Finance, 52, 9751005.

Andersen, T.G. and T. Bollerslev (1997b), "Intraday Periodicity and Volatility Persistence in Financial Markets," Journal of Empirical Finance, 4, 115-158.

Andersen, T.G. and T. Bollerslev (1998), “Answering the Skeptics: Yes, Standard Volatility Models Do Provide Accurate Forecasts," International Economic Review, 39, 885-905.

Andersen, T.G., T. Bollerslev and F.X. Diebold (2003), "Parametric and Non-Parametric Volatility Measurement," in Handbook of Financial Econometrics (L.P Hansen and Y. Aït-Sahalia, eds.). Elsevier Science, New York, forthcoming.

Andersen, T.G., T. Bollerslev, F.X. Diebold and H. Ebens (2001), "The Distribution of Realized Stock Return Volatility," Journal of Financial Economics, 61, 43-76.

Andersen, T.G., T. Bollerslev, F.X. Diebold and P. Labys (2000), “Great Realizations,” Risk, 13, 105-108.

Andersen, T.G., T. Bollerslev, F.X. Diebold and P. Labys (2001), "The Distribution of Realized Exchange Rate Volatility," Journal of the American Statistical Association, 96, 42-55.

Andersen, T.G., T. Bollerslev, F.X. Diebold and P. Labys (2003), "Modeling and Forecasting Realized Volatility," Econometrica, 71, 579-625.

Andersen, T.G., T. Bollerslev, F.X. Diebold and C. Vega (2003a), "Micro Effects of Macro Announcements: Real-Time Price Discovery in Foreign Exchange," American Economic Review, 93, 38-62.

Andersen, T.G., T. Bollerslev, F.X. Diebold and C. Vega (2003b), "The Evolving Effects of Macroeconomic News on Global Stock, Bond and Foreign Exchange Markets," Work in Progress, Northwestern University, Duke University, University of Pennsylvania, and University of Rochester.

Andersen, T.G., T. Bollerslev and N. Meddahi (2002), "Correcting the Errors: A Note on Volatility Forecast Evaluation based on High-frequency Data and realized Volatilities," Manuscript, Northwestern University, Duke University and University of Montreal. 
Andersen, T.G., T. Bollerslev and N. Meddahi (2004), "Analytic Evaluation of Volatility Forecasts," International Economic Review, forthcoming.

Andreou, E. and E. Ghysels (2002), "Rolling-Sample Volatility Estimators: Some New Theoretical, Simulation, and Empirical Results," Journal of Business and Economic Statistics, 20, 363-376.

Areal, N.M.P.C. and S.J. Taylor (2002), “The Realized Volatility of FTSE-100 Futures Prices,” Journal of Futures Market, 22, 627-648.

Bai, X., J.R. Russell and G.C. Tiao (2001), "Beyond Merton's Utopia: Effects of Non-Normality and Dependence on the Precision of Variance Estimates Using High-Frequency Financial Data," Manuscript, University of Chicago.

Baillie, R.T., T. Bollerslev, and H.O. Mikkelsen (1996), "Fractionally Integrated Generalized Autoregressive Conditional Heteroskedasticity," Journal of Econometrics, 74, 3-30.

Ball, C.A. and W.N. Torous (1983), “A Simplified Jump Process for Common Stock Returns,” Journal of Financial and Quantitative Analysis, 18, 53-65.

Bandi, F.M. and J.R. Russell (2003), "Microstructure Noise, Realized Volatility and Optimal Sampling," Manuscript, University of Chicago.

Barndorff-Nielsen, O.E., S.E. Graversen and N. Shephard (2003), "Power Variation and Stochastic Volatility: A Review and Some New Results," Journal of Applied Probability, forthcoming.

Barndorff-Nielsen, O.E. and N. Shephard (2002a), "Econometric Analysis of Realised Volatility and its use in Estimating Stochastic Volatility Models," Journal of the Royal Statistical Society, 64, 253-280.

Barndorff-Nielsen, O.E. and N. Shephard (2002b), "Estimating Quadratic Variation Using Realized Variance," Journal of Applied Econometrics, 17, 457-478.

Barndorff-Nielsen, O.E. and N. Shephard (2003a), "Realised Power Variation and Stochastic Volatility," Bernoulli, 9, 243-265.

Barndorff-Nielsen, O.E. and N. Shephard (2003b), "How Accurate is the Asymptotic Approximation to the Distribution of Realised Volatility," in Identification and Inference for Econometric Models. A Festschrift in Honour of T.J. Rothenberg (D. Andrews, J. Powell, P.A. Ruud, and J. Stock, eds.). Cambridge, UK: Cambridge University Press.

Barndorff-Nielsen, O.E. and N. Shephard (2003c), "Power and Bipower Variation with Stochastic Volatility and Jumps," Manuscript, Oxford University.

Barndorff-Nielsen, O.E. and N. Shephard (2003d), "Econometrics of Testing for Jumps in Financial Economics Using Bipower Variation," Manuscript, Oxford University.

Barucci, E. and R. Renò (2002), "On Measuring Volatility and the GARCH Forecasting Performance," Journal of International Financial Markets, Institutions \& Money, 12, 183-200.

Basak, G., N.H. Chan, and W. Palma (2001), "The Approximation of Long-Memory Processes by an ARMA Model," Journal of Forecasting, 20, 367-389.

Bates, D.S. (2000), "Post- 87 Crash fears in the S\&P500 Futures Option Market," Journal of Econometrics, 94, 181-238. 
Bates, D.S. (2003), “Maximum Likelihood Estimation of Latent Affine Processes,” NBER Working Paper No.9673.

Bollen, B. and B. Inder (2002), "Estimating Daily Volatility in Financial Markets Utilizing Intraday Data," Journal of Empirical Finance, 9, 551-562.

Bollerslev, T. (1986), “Generalized Autoregressive Conditional Heteroskedasticity," Journal of Econometrics, $31,307-327$.

Bollerslev, T., R.Y. Chou and K.F. Kroner (1992), "ARCH Modeling in Finance: A Review of the Theory and Empirical Evidence," Journal of Econometrics, 52, 5-59.

Bollerslev, T., R.F. Engle and D.B. Nelson (1994), “ARCH Models,” in Handbook of Econometrics (R.F. Engle and D.L. McFadden, eds.). Elsevier Science, New York, 2961-3031.

Bollerslev, T. and J.H. Wright (2001), "Volatility Forecasting, High-Frequency Data, and Frequency Domain Inference," Review of Economics and Statistics, 83, 596-602.

Bollerslev, T. and H. Zhou (2002), "Estimating Stochastic Volatility Diffusions Using Conditional Moments of Integrated Volatility," Journal of Econometrics, 109, 33-65.

Breidt, F.J., N. Crato and P. de Lima (1998), “The Detection and Estimation of Long-Memory in Stochastic Volatility," Journal of Econometrics, 83, 325-348.

Calvet, L. and A. Fisher (2001), "Forecasting Multifractal Volatility," Journal of Econometrics, 105, 27-58.

Calvet, L. and A. Fisher (2002), "Multifractality in Asset Returns: Theory and Evidence," Review of Economics and Statistics, 84, 381-406.

Chan, W.H. and J.M. Maheu (2002), "Conditional Jump Dynamics in Stock Market Returns," Journal of Business and Economic Statistics, 20, 377-389.

Chernov, M., A.R. Gallant, E. Ghysels, and G. Tauchen (2003), “Alternative Models for Stock Price Dynamics," Journal of Econometrics, 116, 225-257.

Comte, F. and E. Renault (1998), "Long Memory in Continuous Time Stochastic Volatility Models," Mathematical Finance, 8, 291-323.

Corsi, F. (2003), “A Simple Long Memory Model of Realized Volatility,” Manuscript, University of Southern Switzerland.

Corsi, F., Zumbach, U.A. Müller and M. Dacorogna (2001), "Consistent High-Precision Volatility from Highfrequency Data," Economic Notes, 30, 183-204.

Cox, D.R. (1991), “Long-Range Dependence, Non-Linearity and Time Irreversibility,” Journal of Time Series Analysis, 12, 329-335.

Curci, G. and F. Corsi (2003), "A Discrete Sine Transform Approach for Realized Volatility Measurement," Manuscript, University of Pisa.

Dacorogna, M.M., U.A. Müller, R.J. Nagler, R.B. Olsen and O.V. Pictet (1993), “A Geographical Model for the Daily and Weekly Seasonal Volatility in the Foreign Exchange Market," Journal of International Money and Finance, 12, 413-438. 
Dacorogna, M.M., R. Gencay, U.A. Müller, O.V. Pictet and R.B. Olsen (2001). An Introduction to HighFrequency Finance. San Diego: Academic Press.

Das, S.R. (2002), “The Surprise Element: Jumps in Interest Rates,” Journal of Econometrics, 106, 27-65.

Deo, R., C. Hurvich, and Y. Lu (2003), “On Forecasting Realized Volatility with High Frequency Returns," Manuscript, New York University.

Diebold, F.X. and J.A. Lopez (1996), "Forecast Evaluation and Combination," in Handbook of Statistics, Vol. 14 (G.S. Maddala and C.R. Rao, eds.). North Holland, Amsterdam, 241-268.

Ding, Z., C.W.J. Granger and R.F. Engle (1993), “A Long-Memory Property of Stock Market Returns and a New Model,” Journal of Empirical Finance, 1, 83-106.

Drost, F.C., T.E. Nijman and B.J.M. Werker (1998), "Estimation and Testing in Models Containing Both Jumps and Conditional Heteroskedasticity," Journal of Business and Economic Statistics, 16, 237243.

Engle, R.F. (1982), "Autoregressive Conditional Heteroskedasticity with Estimates of the variance of U.K. Inflation," Econometrica, 45, 987-1007.

Engle, R.F. (2002), “New Frontiers for ARCH Models,” Journal of Applied Econometrics, 17, 425-446.

Engle, R.F. and G.J. Lee (1999), “A Permanent and Transitory Component Model of Stock Return Volatility," in Cointegration, Causality, and Forecasting: A Festschrift in Honor of Clive W.J. Granger (R.F. Engle and H. White, eds.). Oxford, UK: Oxford University Press.

Engle, R.F. and V. Ng (1993), "Measuring and testing the Impact of News on Volatility," Journal of Finance, 48, 1749-1778.

Eraker, B., M.S. Johannes and N.G. Polson (2003), "the Impact of Jumps in Volatility," Journal of Finance, $58,1269-1300$.

Fleming, J., C. Kirby and B. Ostdiek (2003), "The Economic Value of Volatility Timing Using Realized Volatility," Journal of Financial Economics, 67, 473-509.

Forsberg, L. and T. Bollerslev (2002), "Bridging the Gap Between the Distribution of Realized (ECU) Volatility and ARCH Modeling (of the Euro): The GARCH-NIG Model," Journal of Applied Econometrics, 17, 535-548.

Gallant, A.R., C.T. Hsu and G. Tauchen (1999), "Using Daily Range Data to Calibrate Volatility Diffusions and Extract the Forward Integrated Variance," Review of Economics and Statistics, 81, 617-631.

Ghysels, E., A. Harvey and E. Renault (1996), "Stochastic Volatility," in Handbook of Statistics Vol. 14 (G.S. Maddala and C.R. Rao, eds.). North Holland, Amsterdam,119-191.

Ghysels, E, P. Santa-Clara and R. Valkanov (2002), "The MIDAS Touch: Mixed Data Sampling Regression Models," Manuscript, University of North Carolina and UCLA.

Ghysels, E, P. Santa-Clara and R. Valkanov (2003), "Predicting Volatility: Getting the Most out of Return Data Sampled at Different Frequencies," Manuscript, University of North Carolina and UCLA.

Giot, P. and S. Laurent (2003), "Modeling Daily Value-at-Risk Using Realized Volatility and ARCH Type Models," Journal of Empirical Finance, forthcoming. 
Glosten, L.R., J. Jaganathan, and D. Runkle (1993), "On the Relation between the Expected Value and the Volatility of the Nominal Excess Returns on Stocks," Journal of Finance, 48, 1779-1801.

Hansen, P.R. and A. Lunde (2003), “A Forecast Comparison of Volatility Models: Does Anything beat a GARCH(1,1)?," Manuscript, Brown University.

Hol, E. and S.J. Koopman, (2002), "Stock Index Volatility Forecasting with High Frequency Data," Manuscript, Free University Amsterdam.

Hsu, N.J. and F.J. Breidt (2003), "Bayesian Analysis of Fractionally Integrated ARMA with Additive Noise," Journal of Forecasting, 22, forthcoming.

Huang, X. and G. Tauchen (2003), “The Relative Contribution of Jumps to Total Price Variation,” Work in Progress, Duke University.

Johannes, M.S., R. Kumar and N.G. Polson (1999), "State Dependent Jump Models: How do US Equity Markets Jump?” Manuscript, University of Chicago.

Jorion, P. (1988), “On Jump Processes in the Foreign Exchange and Stock Markets," Review of Financial Studies, 1, 427-445.

Khalaf, L., J.-D. Saphores and J.-F. Bilodeau (2003), "Simulation-Based Exact Jump Tests in Models with Conditional Heteroskedasticity," Journal of Economic Dynamics and Control, 28, 531-553.

Maheu, J.M. and T.H. McCurdy (2003), "News Arrival, Jump Dynamics and Volatility Components for Individual Stock Returns," Journal of Finance, forthcoming.

Man, K.S. (2003), “Long Memory Time Series and Short Term Forecasts,” International Journal of Forecasting, 19, 477-491.

Martens, M. (2002), "Measuring and Forecasting S\&P500 Index Futures Volatility Using High-Frequency Data," Journal of Futures Markets, 22, 497-518.

Martens, M., (2003), “Estimating Unbiased and Precise Realized Covariances,” Manuscript, Erasmus University Rotterdam.

Martens, M., D. van Dijk and M. de Pooter (2003), "Modeling and Forecasting \&P500 Volatility: LongMemory, Structural Breaks and Nonlinearity," Manuscript, Erasmus University Rotterdam.

Meddahi, N. (2002), “A Theoretical Comparison Between Integrated and Realized Volatility,” Journal of Applied Econometrics, 17, 479-508.

Merton, R.C. (1976), “Option Pricing when Underlying Stock returns and Discontinuous,” Journal of Financial Economics, 3, 125-144.

Merton, R.C. (1980), "On Estimating the Expected Return on the Market: An Exploratory Investigation," Journal of Financial Economics, 8, 323-361.

Müller, U.A., M.M. Dacorogna, R.B. Olsen, O.V. Puctet, M. Schwarz, and C. Morgenegg (1990), "Statistical Study of Foreign Exchange Rates, Empirical Evidence of a Price Change Scaling Law, and Intraday Analysis," Journal of Banking and Finance, 14, 1189-1208.

Neely, C.J. (1999), “Target Zones and Conditional Volatility: The Role of Realignments," Journal of Empirical Finance, 6, 177-192. 
Nelson, D.B. (1991), “Conditional Heteroskedasticity in Asset returns: A New Approach,” Econometrica, 59, 347-370.

Nelson, D.B. (1992), "Filtering and Forecasting with Misspecified ARCH Models I: Getting the Right Variance with the Wrong Model," Journal of Econometrics, 52, 61-90.

O’Connell, P.E. (1971), “A Simple Stochastic Modelling of Hurst's Law,” Proceedings of International Symposium on Mathematical Models in Hydrology, 1, 169-187.

Pagan, A.R. and G.W. Schwert (1990), “Alternative Models for Conditional Volatility,” Journal of Econometrics, 45, 267-290.

Pan, J. (2002), "the Jump-Risk Premia Implicit in Options: Evidence from an Integrated Time Series Study," Journal of Financial Economics, 63, 3-50.

Pong, S., M.B. Shackleton, S.J. Taylor and X. Xu (2003), "Forecasting Currency Volatility: A Comparison of Implied Volatilities and AR(FI)MA Models," Manuscript, Lancaster University.

Robinson, P.M. (1991), “Testing for Strong Serial Correlation and Dynamic Conditional Heteroskedasticity in Multiple Regressions," Journal of Econometrics, 47, 67-84.

Shephard, N. (1996), "Statistical Aspects of ARCH and Stochastic Volatility Models" in Time Series Models in Econometrics, Finance, and Other Fields (D.R. Cox, D.V. Hinkley, and O.E. Barndorff-Nielsen, eds.). Chapman and Hall, London, UK, 1-67.

Tiao, G.C. and R.S. Tsay (1994), "Some Advances in Non-Linear and Adaptive Modeling in Time Series," Journal of Forecasting, 14, 109-131.

Thomakos, D.D. and T. Wang (2003), "Realized Volatility in the Futures Market," Journal of Empirical Finance, 10, 321-353.

Vlaar, P.J.G. and F.C. Palm (1993), "The Message in Weekly Exchange Rates in the European Monetary System: Mean Reversion, Conditional Heteroskedasticity, and Jumps," Journal of Business and Economic Statistics, 11, 351-360. 
Table 1A

Summary Statistics for Daily DM/\$ Realized Volatilities and Jumps

\begin{tabular}{llllllc}
\hline & $R V_{t}$ & $R V_{t}^{1 / 2}$ & $\log \left(R V_{t}\right)$ & $J_{t}$ & $J_{t}^{1 / 2}$ & $\log \left(J_{t}+1\right)$ \\
Mean & 0.508 & 0.670 & -0.915 & 0.037 & 0.129 & 0.033 \\
St.Dev. & 3.925 & 0.245 & 0.657 & 0.110 & 0.142 & 0.072 \\
Skewness & 3.925 & 1.784 & 0.408 & 16.52 & 2.496 & 7.787 \\
Kurtosis & 26.88 & 8.516 & 3.475 & 434.2 & 18.20 & 108.5 \\
Min. & 0.052 & 0.225 & -2.961 & 0.000 & 0.000 & 0.000 \\
Max. & 5.245 & 2.290 & 1.657 & 3.566 & 1.889 & 1.519 \\
LB $_{10}$ & 3786 & 5714 & 7060 & 16.58 & 119.4 & 63.19 \\
\hline
\end{tabular}

Table 1B

Summary Statistics for Daily S\&P500 Realized Volatilities and Jumps

\begin{tabular}{llllllc}
\hline & $R V_{t}$ & $R V_{t}^{1 / 2}$ & $\log \left(R V_{t}\right)$ & $J_{t}$ & $J_{t}^{1 / 2}$ & $\log \left(J_{t}+1\right)$ \\
Mean & 1.126 & 0.923 & -0.411 & 0.164 & 0.232 & 0.097 \\
St.Dev. & 1.838 & 0.527 & 0.972 & 0.959 & 0.332 & 0.237 \\
Skewness & 7.689 & 2.534 & 0.351 & 20.71 & 5.547 & 6.336 \\
Kurtosis & 96.43 & 14.86 & 3.142 & 555.4 & 59.01 & 58.39 \\
Min. & 0.033 & 0.181 & -3.421 & 0.000 & 0.000 & 0.000 \\
Max. & 36.42 & 6.035 & 3.595 & 31.88 & 5.646 & 3.493 \\
LB $_{10}$ & 5915 & 12335 & 15693 & 596.1 & 1990 & 2455 \\
\hline
\end{tabular}

Table 1C

Summary Statistics for Daily U.S. T-Bond Realized Volatilities and Jumps

\begin{tabular}{llllllc}
\hline & $R V_{t}$ & $R V_{t}^{1 / 2}$ & $\log \left(R V_{t}\right)$ & $J_{t}$ & $J_{t}^{1 / 2}$ & $\log \left(J_{t}+1\right)$ \\
Mean & 0.284 & 0.504 & -1.476 & 0.036 & 0.146 & 0.033 \\
St.Dev. & 0.224 & 0.174 & 0.646 & 0.069 & 0.120 & 0.055 \\
Skewness & 3.080 & 1.359 & 0.233 & 8.618 & 1.680 & 5.617 \\
Kurtosis & 20.08 & 6.190 & 3.135 & 141.0 & 9.988 & 56.20 \\
Min. & 0.022 & 0.151 & -3.782 & 0.000 & 0.000 & 0.000 \\
Max. & 2.968 & 1.723 & 1.088 & 1.714 & 1.309 & 0.998 \\
LB $_{10}$ & 978.6 & 1677 & 2184 & 22.82 & 33.79 & 30.09 \\
\hline
\end{tabular}

Key: The first six rows in each of the panels report the sample mean, standard deviation, skewness and kurtosis, along with the sample minimum and maximum. The rows labeled $\mathrm{LB}_{10}$ give the Ljung-Box test statistic for up to tenth order serial correlation. The daily realized volatilities and jumps for the $\mathrm{DM} / \$$ in Panel A are constructed from five-minute returns spanning the period from December 1986 through June 1999, for a total of 3,045 daily observations. The daily realized volatilities and jumps for the S\&P500 and U.S. T-Bonds in Panels B and C are based on five-minute returns from January 1990 through December 2002, for a total of 3,262 observations. 
Table 2A

Daily, Weekly, and Monthly DM/\$ HAR-RV-J Regressions

$$
\begin{gathered}
R V_{t, t+h}=\beta_{0}+\beta_{D} R V_{t}+\beta_{W} R V_{t-5, t}+\beta_{M} R V_{t-22, t}+\beta_{J} J_{t}+\epsilon_{t, t+h} \\
\left(R V_{t, t+h}\right)^{1 / 2}=\beta_{0}+\beta_{D} R V_{t}^{1 / 2}+\beta_{W}\left(R V_{t-5, t}\right)^{1 / 2}+\beta_{M}\left(R V_{t-22, t}\right)^{1 / 2}+\beta_{J} J_{t}^{1 / 2}+\epsilon_{t, t+h} \\
\log \left(R V_{t, t+h}\right)=\beta_{0}+\beta_{D} \log \left(R V_{t}\right)+\beta_{W} \log \left(R V_{t-5, t}\right)+\beta_{M} \log \left(R V_{t-22, t}\right)+\beta_{J} \log \left(J_{t}+1\right)+\epsilon_{t, t+h}
\end{gathered}
$$

\begin{tabular}{|c|c|c|c|c|c|c|c|c|c|}
\hline \multirow[b]{2}{*}{$h$} & \multicolumn{3}{|c|}{$R V_{t, t+h}$} & \multicolumn{3}{|c|}{$\left(R V_{t, t+h}\right)^{1 / 2}$} & \multicolumn{3}{|c|}{$\log \left(R V_{t, t+h}\right)$} \\
\hline & 1 & 5 & 22 & 1 & 5 & 22 & 1 & 5 & 22 \\
\hline$\beta_{0}$ & $\begin{array}{c}0.083 \\
(0.015)\end{array}$ & $\begin{array}{c}0.132 \\
(0.018)\end{array}$ & $\begin{array}{c}0.230 \\
(0.025)\end{array}$ & $\begin{array}{c}0.096 \\
(0.015)\end{array}$ & $\begin{array}{c}0.159 \\
(0.021)\end{array}$ & $\begin{array}{l}0.293 \\
(0.034)\end{array}$ & $\begin{array}{l}-0.122 \\
(0.021)\end{array}$ & $\begin{array}{l}-0.142 \\
(0.030)\end{array}$ & $\begin{array}{l}-0.269 \\
(0.048)\end{array}$ \\
\hline$\beta_{D}$ & $\begin{array}{c}0.430 \\
(0.043)\end{array}$ & $\begin{array}{c}0.222 \\
(0.040)\end{array}$ & $\begin{array}{c}0.110 \\
(0.022)\end{array}$ & $\begin{array}{c}0.392 \\
(0.033)\end{array}$ & $\begin{array}{c}0.216 \\
(0.028)\end{array}$ & $\begin{array}{c}0.124 \\
(0.020)\end{array}$ & $\begin{array}{c}0.408 \\
(0.030)\end{array}$ & $\begin{array}{c}0.252 \\
(0.029)\end{array}$ & $\begin{array}{c}0.162 \\
(0.027)\end{array}$ \\
\hline$\beta_{W}$ & $\begin{array}{c}0.196 \\
(0.063)\end{array}$ & $\begin{array}{c}0.216 \\
(0.055)\end{array}$ & $\begin{array}{c}0.218 \\
(0.043)\end{array}$ & $\begin{array}{c}0.248 \\
(0.046)\end{array}$ & $\begin{array}{c}0.264 \\
(0.050)\end{array}$ & $\begin{array}{l}0.243 \\
(0.040)\end{array}$ & $\begin{array}{c}0.271 \\
(0.042)\end{array}$ & $\begin{array}{l}0.265 \\
(0.051)\end{array}$ & $\begin{array}{c}0.221 \\
(0.039)\end{array}$ \\
\hline$\beta_{M}$ & $\begin{array}{c}0.244 \\
(0.061)\end{array}$ & $\begin{array}{c}0.323 \\
(0.068)\end{array}$ & $\begin{array}{c}0.225 \\
(0.062)\end{array}$ & $\begin{array}{c}0.223 \\
(0.041)\end{array}$ & $\begin{array}{c}0.296 \\
(0.056)\end{array}$ & $\begin{array}{c}0.219 \\
(0.063)\end{array}$ & $\begin{array}{c}0.212 \\
(0.036)\end{array}$ & $\begin{array}{c}0.284 \\
(0.054)\end{array}$ & $\begin{array}{c}0.226 \\
(0.065)\end{array}$ \\
\hline$\beta_{J}$ & $\begin{array}{l}-0.486 \\
(0.096)\end{array}$ & $\begin{array}{l}-0.297 \\
(0.070)\end{array}$ & $\begin{array}{l}-0.166 \\
(0.056)\end{array}$ & $\begin{array}{l}-0.103 \\
(0.039)\end{array}$ & $\begin{array}{l}-0.047 \\
(0.031)\end{array}$ & $\begin{array}{l}-0.026 \\
(0.028)\end{array}$ & $\begin{array}{l}-0.762 \\
(0.161)\end{array}$ & $\begin{array}{l}-0.590 \\
(0.176)\end{array}$ & $\begin{array}{l}-0.395 \\
(0.178)\end{array}$ \\
\hline$R_{H A R-R V-J}^{2}$ & 0.364 & 0.417 & 0.353 & 0.431 & 0.472 & 0.386 & 0.476 & 0.502 & 0.407 \\
\hline$R_{H A R}^{2}$ & 0.252 & 0.261 & 0.215 & 0.261 & 0.272 & 0.225 & 0.160 & 0.159 & 0.138 \\
\hline
\end{tabular}

Key: The table reports the OLS estimates for daily $(\mathrm{h}=1)$ and overlapping weekly $(\mathrm{h}=5)$ and monthly $(\mathrm{h}=22)$ HAR-RV-J volatility forecast regressions. The realized volatilities and jumps are constructed from five-minute returns spanning the period from December 1986 through June 1999, for a total of 3,045 daily observations. The standard errors reported in parentheses are based on a Newey-West/Bartlett correction allowing for serial correlation of up to order $5(\mathrm{~h}=1), 10(\mathrm{~h}=5)$ and $44(\mathrm{~h}=22)$, respectively. The last two rows labeled $R_{H A R-R V-J}^{2}$ and $R_{H A R}^{2}$ give the coefficients of multiple correlation from the HARRV-J model along with a HAR model without any jumps replacing the realized volatilities on the righthand-side of the regression with the corresponding lagged daily, weekly, and monthly squared returns. 
Table 2B

Daily, Weekly, and Monthly S\&P500 HAR-RV-J Regressions

$$
\begin{gathered}
R V_{t, t+h}=\beta_{0}+\beta_{D} R V_{t}+\beta_{W} R V_{t-5, t}+\beta_{M} R V_{t-22, t}+\beta_{J} J_{t}+\epsilon_{t, t+h} \\
\left(R V_{t, t+h}\right)^{1 / 2}=\beta_{0}+\beta_{D} R V_{t}^{1 / 2}+\beta_{W}\left(R V_{t-5, t}\right)^{1 / 2}+\beta_{M}\left(R V_{t-22, t}\right)^{1 / 2}+\beta_{J} J_{t}^{1 / 2}+\epsilon_{t, t+h} \\
\log \left(R V_{t, t+h}\right)=\beta_{0}+\beta_{D} \log \left(R V_{t}\right)+\beta_{W} \log \left(R V_{t-5, t}\right)+\beta_{M} \log \left(R V_{t-22, t}+\beta_{J} \log \left(J_{t}+1\right)+\epsilon_{t, t+h}\right.
\end{gathered}
$$

\begin{tabular}{|c|c|c|c|c|c|c|c|c|c|}
\hline \multirow[b]{2}{*}{$h$} & \multicolumn{3}{|c|}{$R V_{t, t+h}$} & \multicolumn{3}{|c|}{$\left(R V_{t, t+h}\right)^{1 / 2}$} & \multicolumn{3}{|c|}{$\log \left(R V_{t, t+h}\right)$} \\
\hline & 1 & 5 & 22 & 1 & 5 & 22 & 1 & 5 & 22 \\
\hline$\beta_{0}$ & $\begin{array}{c}0.093 \\
(0.054)\end{array}$ & $\begin{array}{c}0.187 \\
(0.065)\end{array}$ & $\begin{array}{c}0.387 \\
(0.072)\end{array}$ & $\begin{array}{c}0.063 \\
(0.020)\end{array}$ & $\begin{array}{c}0.105 \\
(0.030)\end{array}$ & $\begin{array}{c}0.210 \\
(0.038)\end{array}$ & $\begin{array}{l}-0.072 \\
(0.014)\end{array}$ & $\begin{array}{l}-0.003 \\
(0.019)\end{array}$ & $\begin{array}{c}0.018 \\
(0.036)\end{array}$ \\
\hline$\beta_{D}$ & $\begin{array}{c}0.317 \\
(0.091)\end{array}$ & $\begin{array}{c}0.213 \\
(0.063)\end{array}$ & $\begin{array}{c}0.106 \\
(0.039)\end{array}$ & $\begin{array}{c}0.356 \\
(0.043)\end{array}$ & $\begin{array}{c}0.253 \\
(0.035)\end{array}$ & $\begin{array}{c}0.161 \\
(0.029)\end{array}$ & $\begin{array}{c}0.325 \\
(0.027)\end{array}$ & $\begin{array}{c}0.220 \\
(0.023)\end{array}$ & $\begin{array}{c}0.144 \\
(0.023)\end{array}$ \\
\hline$\beta_{W}$ & $\begin{array}{c}0.499 \\
(0.113)\end{array}$ & $\begin{array}{c}0.441 \\
(0.097)\end{array}$ & $\begin{array}{c}0.291 \\
(0.091)\end{array}$ & $\begin{array}{c}0.369 \\
(0.064)\end{array}$ & $\begin{array}{c}0.404 \\
(0.067)\end{array}$ & $\begin{array}{c}0.292 \\
(0.069)\end{array}$ & $\begin{array}{c}0.348 \\
(0.041)\end{array}$ & $\begin{array}{c}0.368 \\
(0.049)\end{array}$ & $\begin{array}{c}0.262 \\
(0.048)\end{array}$ \\
\hline$\beta_{M}$ & $\begin{array}{c}0.165 \\
(0.064)\end{array}$ & $\begin{array}{c}0.215 \\
(0.079)\end{array}$ & $\begin{array}{c}0.276 \\
(0.086)\end{array}$ & $\begin{array}{c}0.235 \\
(0.039)\end{array}$ & $\begin{array}{c}0.266 \\
(0.057)\end{array}$ & $\begin{array}{c}0.356 \\
(0.068)\end{array}$ & $\begin{array}{c}0.285 \\
(0.031)\end{array}$ & $\begin{array}{c}0.339 \\
(0.046)\end{array}$ & $\begin{array}{c}0.453 \\
(0.053)\end{array}$ \\
\hline$\beta_{J}$ & $\begin{array}{l}-0.436 \\
(0.094)\end{array}$ & $\begin{array}{l}-0.218 \\
(0.079)\end{array}$ & $\begin{array}{l}-0.070 \\
(0.067)\end{array}$ & $\begin{array}{l}-0.194 \\
(0.045)\end{array}$ & $\begin{array}{l}-0.122 \\
(0.039)\end{array}$ & $\begin{array}{l}-0.047 \\
(0.046)\end{array}$ & $\begin{array}{l}-0.238 \\
(0.058)\end{array}$ & $\begin{array}{l}-0.164 \\
(0.063)\end{array}$ & $\begin{array}{l}-0.083 \\
(0.080)\end{array}$ \\
\hline$R_{H A R-R V-J}^{2}$ & 0.412 & 0.571 & 0.474 & 0.599 & 0.695 & 0.630 & 0.678 & 0.755 & 0.719 \\
\hline$R_{H A R}^{2}$ & 0.249 & 0.242 & 0.159 & 0.320 & 0.320 & 0.273 & 0.196 & 0.216 & 0.167 \\
\hline
\end{tabular}

Key: The table reports the OLS estimates for daily $(\mathrm{h}=1)$ and overlapping weekly $(\mathrm{h}=5)$ and monthly $(\mathrm{h}=22)$ HAR-RV-J volatility forecast regressions. The realized volatilities and jumps are constructed from five-minute returns spanning the period from January 1990 through December 2002, for a total of 3,262 daily observations. The standard errors reported in parentheses are based on a Newey-West/Bartlett correction allowing for serial correlation of up to order $5(\mathrm{~h}=1), 10(\mathrm{~h}=5)$ and $44(\mathrm{~h}=22)$, respectively. The last two rows labeled $R_{H A R-R V-J}^{2}$ and $R_{H A R}^{2}$ give the coefficients of multiple correlation from the HARRV-J along with a HAR model without jumps replacing the realized volatilities on the right-hand-side of the regression with the corresponding lagged daily, weekly, and monthly squared returns. 
Table 2C

Daily, Weekly, and Monthly U.S. T-Bond HAR-RV-J Regressions

$$
\begin{gathered}
R V_{t, t+h}=\beta_{0}+\beta_{D} R V_{t}+\beta_{W} R V_{t-5, t}+\beta_{M} R V_{t-22, t}+\beta_{J} J_{t}+\epsilon_{t, t+h} \\
\left(R V_{t, t+h}\right)^{1 / 2}=\beta_{0}+\beta_{D} R V_{t}^{1 / 2}+\beta_{W}\left(R V_{t-5, t}\right)^{1 / 2}+\beta_{M}\left(R V_{t-22, t}\right)^{1 / 2}+\beta_{J} J_{t}^{1 / 2}+\epsilon_{t, t+h} \\
\log \left(R V_{t, t+h}\right)=\beta_{0}+\beta_{D} \log \left(R V_{t}\right)+\beta_{W} \log \left(R V_{t-5, t}\right)+\beta_{M} \log \left(R V_{t-22, t}+\beta_{J} \log \left(J_{t}+1\right)+\epsilon_{t, t+h}\right.
\end{gathered}
$$

\begin{tabular}{|c|c|c|c|c|c|c|c|c|c|}
\hline \multirow[b]{2}{*}{$h$} & \multicolumn{3}{|c|}{$R V_{t, t+h}$} & \multicolumn{3}{|c|}{$\left(R V_{t, t+h}\right)^{1 / 2}$} & \multicolumn{3}{|c|}{$\log \left(R V_{t, t+h}\right)$} \\
\hline & 1 & 5 & 22 & 1 & 5 & 22 & 1 & 5 & 22 \\
\hline$\beta_{0}$ & $\begin{array}{c}0.079 \\
(0.012)\end{array}$ & $\begin{array}{c}0.089 \\
(0.013)\end{array}$ & $\begin{array}{c}0.126 \\
(0.016)\end{array}$ & $\begin{array}{c}0.122 \\
(0.017)\end{array}$ & $\begin{array}{c}0.153 \\
(0.020)\end{array}$ & $\begin{array}{c}0.224 \\
(0.030)\end{array}$ & $\begin{array}{l}-0.365 \\
(0.044)\end{array}$ & $\begin{array}{l}-0.332 \\
(0.050)\end{array}$ & $\begin{array}{l}-0.482 \\
(0.077)\end{array}$ \\
\hline$\beta_{D}$ & $\begin{array}{c}0.069 \\
(0.031)\end{array}$ & $\begin{array}{c}0.079 \\
(0.016)\end{array}$ & $\begin{array}{c}0.042 \\
(0.010)\end{array}$ & $\begin{array}{c}0.065 \\
(0.025)\end{array}$ & $\begin{array}{c}0.077 \\
(0.014)\end{array}$ & $\begin{array}{c}0.043 \\
(0.009)\end{array}$ & $\begin{array}{c}0.112 \\
(0.024)\end{array}$ & $\begin{array}{c}0.096 \\
(0.015)\end{array}$ & $\begin{array}{c}0.062 \\
(0.012)\end{array}$ \\
\hline$\beta_{W}$ & $\begin{array}{c}0.316 \\
(0.049)\end{array}$ & $\begin{array}{c}0.213 \\
(0.042)\end{array}$ & $\begin{array}{c}0.162 \\
(0.037)\end{array}$ & $\begin{array}{c}0.320 \\
(0.044)\end{array}$ & $\begin{array}{c}0.212 \\
(0.039)\end{array}$ & $\begin{array}{c}0.166 \\
(0.034)\end{array}$ & $\begin{array}{c}0.321 \\
(0.043)\end{array}$ & $\begin{array}{c}0.203 \\
(0.038)\end{array}$ & $\begin{array}{c}0.159 \\
(0.031)\end{array}$ \\
\hline$\beta_{M}$ & $\begin{array}{c}0.360 \\
(0.057)\end{array}$ & $\begin{array}{c}0.422 \\
(0.054)\end{array}$ & $\begin{array}{c}0.372 \\
(0.068)\end{array}$ & $\begin{array}{c}0.361 \\
(0.046)\end{array}$ & $\begin{array}{c}0.432 \\
(0.050)\end{array}$ & $\begin{array}{c}0.382 \\
(0.067)\end{array}$ & $\begin{array}{c}0.366 \\
(0.045)\end{array}$ & $\begin{array}{c}0.442 \\
(0.052)\end{array}$ & $\begin{array}{c}0.382 \\
(0.068)\end{array}$ \\
\hline$\beta_{J}$ & $\begin{array}{l}-0.151 \\
(0.097)\end{array}$ & $\begin{array}{l}-0.195 \\
(0.042)\end{array}$ & $\begin{array}{l}-0.142 \\
(0.033)\end{array}$ & $\begin{array}{l}-0.046 \\
(0.031)\end{array}$ & $\begin{array}{l}-0.059 \\
(0.018)\end{array}$ & $\begin{array}{l}-0.044 \\
(0.015)\end{array}$ & $\begin{array}{l}-0.895 \\
(0.237)\end{array}$ & $\begin{array}{l}-0.672 \\
(0.129)\end{array}$ & $\begin{array}{l}-0.569 \\
(0.120)\end{array}$ \\
\hline$R_{H A R-R V-J}^{2}$ & 0.124 & 0.305 & 0.344 & 0.166 & 0.329 & 0.363 & 0.196 & 0.348 & 0.381 \\
\hline$R_{H A R}^{2}$ & 0.067 & 0.133 & 0.116 & 0.075 & 0.124 & 0.105 & 0.031 & 0.051 & 0.043 \\
\hline
\end{tabular}

Key: The table reports the OLS estimates for daily $(\mathrm{h}=1)$ and overlapping weekly $(\mathrm{h}=5)$ and monthly $(\mathrm{h}=22)$ HAR-RV-J volatility forecast regressions. The realized volatilities and jumps are constructed from five-minute returns spanning the period from January 1990 through December 2002, for a total of 3,262 daily observations. The standard errors reported in parentheses are based on a Newey-West/Bartlett correction allowing for serial correlation of up to order $5(\mathrm{~h}=1), 10(\mathrm{~h}=5)$ and $44(\mathrm{~h}=22)$, respectively. The last two rows labeled $R_{H A R-R V-J}^{2}$ and $R_{H A R}^{2}$ give the coefficients of multiple correlation from the HARRV-J model along with a HAR model without jumps replacing the realized volatilities on the right-handside of the regression with the corresponding lagged daily, weekly, and monthly squared returns. 
Table 3A

Summary Statistics for Significant Daily DM/\$ Jumps

\begin{tabular}{lccccc}
\hline$\alpha$ & 0.500 & 0.950 & 0.990 & 0.999 & 0.9999 \\
Prop. & 0.694 & 0.215 & 0.116 & 0.058 & 0.036 \\
Mean. & 0.037 & 0.025 & 0.018 & 0.013 & 0.010 \\
St.Dev. & 0.110 & 0.109 & 0.105 & 0.100 & 0.098 \\
LB $_{10}, J_{t, \alpha}$ & 16.58 & 3.37 & 5.08 & 4.87 & 1.36 \\
LB $_{10}, J_{t, \alpha}>0$ & 20.87 & 13.09 & 9.56 & 19.57 & 15.46 \\
\hline
\end{tabular}

Table 3B

Summary Statistics for Significant Daily S\&P500 Jumps

\begin{tabular}{llllll}
\hline$\alpha$ & 0.500 & 0.950 & 0.990 & 0.999 & 0.9999 \\
Prop. & 0.723 & 0.254 & 0.148 & 0.082 & 0.054 \\
Mean. & 0.164 & 0.134 & 0.116 & 0.101 & 0.094 \\
St.Dev. & 0.959 & 0.958 & 0.957 & 0.953 & 0.951 \\
LB $_{10}, J_{t, \alpha}$ & 596.1 & 489.4 & 399.5 & 376.3 & 380.2 \\
LB $_{10}, J_{t, \alpha}>0$ & 33.41 & 62.94 & 90.01 & 92.05 & 215.9 \\
\hline
\end{tabular}

Table 3C

Summary Statistics for Significant Daily U.S. T-Bond Jumps

\begin{tabular}{lccccc}
\hline$\alpha$ & 0.500 & 0.950 & 0.990 & 0.999 & 0.9999 \\
Prop. & 0.817 & 0.336 & 0.209 & 0.118 & 0.067 \\
Mean. & 0.036 & 0.025 & 0.019 & 0.014 & 0.010 \\
St.Dev. & 0.069 & 0.070 & 0.068 & 0.065 & 0.060 \\
LB $_{10}, J_{t, \alpha}$ & 22.8 & 14.9 & 12.5 & 11.4 & 18.8 \\
LB $_{10}, J_{t, \alpha}>0$ & 31.5 & 29.9 & 18.5 & 27.5 & 27.7 \\
\hline
\end{tabular}

Key: The significant jumps for each of the three market, $J_{t, \alpha}$, are determined by equation (19) in the main text. The first row in each of the panels gives the proportion of days with significant jumps for each of the different significance levels $\alpha$. The next two rows report the corresponding mean and standard deviation of the jump time series. The last two sets of rows labeled $\mathrm{LB}_{10}, J_{t, \alpha}$ and $\mathrm{LB}_{10}, J_{t, \alpha}>0$ give the Ljung-Box test statistic for up to tenth order serial correlation in the jump and corresponding zero-one jump indicator series, respectively. 
Table 4A

Daily, Weekly, and Monthly DM/\$ HAR-RV-CJ Regressions

\begin{tabular}{|c|c|c|c|c|c|c|c|c|c|}
\hline \multirow[b]{2}{*}{$h$} & \multicolumn{3}{|c|}{$R V_{t, t+h}$} & \multicolumn{3}{|c|}{$\left(R V_{t, t+h}\right)^{1 / 2}$} & \multicolumn{3}{|c|}{$\log \left(R V_{t, t+h}\right)$} \\
\hline & 1 & 5 & 22 & 1 & 5 & 22 & 1 & 5 & 22 \\
\hline$\beta_{0}$ & $\begin{array}{c}0.087 \\
(0.015)\end{array}$ & $\begin{array}{c}0.135 \\
(0.018)\end{array}$ & $\begin{array}{c}0.235 \\
(0.026)\end{array}$ & $\begin{array}{c}0.097 \\
(0.015)\end{array}$ & $\begin{array}{c}0.158 \\
(0.021)\end{array}$ & $\begin{array}{c}0.292 \\
(0.034)\end{array}$ & $\begin{array}{l}-0.135 \\
(0.019)\end{array}$ & $\begin{array}{l}-0.149 \\
(0.028)\end{array}$ & $\begin{array}{l}-0.273 \\
(0.049)\end{array}$ \\
\hline$\beta_{C D}$ & $\begin{array}{c}0.395 \\
(0.038)\end{array}$ & $\begin{array}{c}0.194 \\
(0.035)\end{array}$ & $\begin{array}{c}0.093 \\
(0.018)\end{array}$ & $\begin{array}{c}0.382 \\
(0.031)\end{array}$ & $\begin{array}{c}0.207 \\
(0.027)\end{array}$ & $\begin{array}{c}0.119 \\
(0.017)\end{array}$ & $\begin{array}{c}0.359 \\
(0.026)\end{array}$ & $\begin{array}{c}0.196 \\
(0.020)\end{array}$ & $\begin{array}{c}0.125 \\
(0.014)\end{array}$ \\
\hline$\beta_{C W}$ & $\begin{array}{c}0.221 \\
(0.066)\end{array}$ & $\begin{array}{c}0.246 \\
(0.056)\end{array}$ & $\begin{array}{c}0.227 \\
(0.044)\end{array}$ & $\begin{array}{c}0.261 \\
(0.047)\end{array}$ & $\begin{array}{c}0.295 \\
(0.050)\end{array}$ & $\begin{array}{c}0.254 \\
(0.042)\end{array}$ & $\begin{array}{c}0.304 \\
(0.038)\end{array}$ & $\begin{array}{c}0.333 \\
(0.046)\end{array}$ & $\begin{array}{c}0.257 \\
(0.040)\end{array}$ \\
\hline$\beta_{C M}$ & $\begin{array}{c}0.230 \\
(0.062)\end{array}$ & $\begin{array}{c}0.309 \\
(0.070)\end{array}$ & $\begin{array}{c}0.230 \\
(0.064)\end{array}$ & $\begin{array}{c}0.207 \\
(0.041)\end{array}$ & $\begin{array}{c}0.268 \\
(0.056)\end{array}$ & $\begin{array}{c}0.209 \\
(0.064)\end{array}$ & $\begin{array}{c}0.210 \\
(0.034)\end{array}$ & $\begin{array}{c}0.258 \\
(0.051)\end{array}$ & $\begin{array}{c}0.213 \\
(0.069)\end{array}$ \\
\hline$\beta_{J D}$ & $\begin{array}{l}-0.080 \\
(0.041)\end{array}$ & $\begin{array}{l}-0.037 \\
(0.032)\end{array}$ & $\begin{array}{l}-0.015 \\
(0.019)\end{array}$ & $\begin{array}{l}-0.017 \\
(0.034)\end{array}$ & $\begin{array}{l}-0.001 \\
(0.023)\end{array}$ & $\begin{array}{c}0.004 \\
(0.012)\end{array}$ & $\begin{array}{l}-0.146 \\
(0.137)\end{array}$ & $\begin{array}{l}-0.020 \\
(0.100)\end{array}$ & $\begin{array}{l}-0.022 \\
(0.064)\end{array}$ \\
\hline$\beta_{J W}$ & $\begin{array}{l}-0.311 \\
(0.171)\end{array}$ & $\begin{array}{l}-0.386 \\
(0.218)\end{array}$ & $\begin{array}{c}0.092 \\
(0.145)\end{array}$ & $\begin{array}{l}-0.037 \\
(0.046)\end{array}$ & $\begin{array}{l}-0.084 \\
(0.064)\end{array}$ & $\begin{array}{c}0.007 \\
(0.047)\end{array}$ & $\begin{array}{l}-0.342 \\
(0.332)\end{array}$ & $\begin{array}{l}-1.036 \\
(0.452)\end{array}$ & $\begin{array}{l}-0.236 \\
(0.381)\end{array}$ \\
\hline$\beta_{J M}$ & $\begin{array}{l}-0.529 \\
(0.524)\end{array}$ & $\begin{array}{l}-0.512 \\
(0.642)\end{array}$ & $\begin{array}{l}-0.289 \\
(0.517)\end{array}$ & $\begin{array}{l}-0.048 \\
(0.062)\end{array}$ & $\begin{array}{c}0.119 \\
(0.097)\end{array}$ & $\begin{array}{c}0.062 \\
(0.123)\end{array}$ & $\begin{array}{l}-0.589 \\
(0.599)\end{array}$ & $\begin{array}{c}0.248 \\
(1.045)\end{array}$ & $\begin{array}{l}-0.379 \\
(1.106)\end{array}$ \\
\hline$R_{H A R-R V-C J}^{2}$ & 0.370 & 0.425 & 0.356 & 0.442 & 0.486 & 0.395 & 0.484 & 0.518 & 0.414 \\
\hline
\end{tabular}

Key: The table reports the OLS estimates for daily $(\mathrm{h}=1)$ and overlapping weekly $(\mathrm{h}=5)$ and monthly $(\mathrm{h}=22)$ HAR-RV-CJ volatility forecast regressions. All of the realized volatility measures are constructed from five-minute returns spanning the period from December 1986 through June 1999, for a total of 3,045 daily observations. The weekly and monthly measures are given by the scaled sum of the corresponding daily measures. The significant daily jump and continuous sample path variability measures are based on equations (19) and (20), respectively, using a critical value of $\alpha=0.999$. The standard errors reported in parentheses are based on a Newey-West/Bartlett correction allowing for serial correlation of up to order 5 $(\mathrm{h}=1), 10(\mathrm{~h}=5)$ and $44(\mathrm{~h}=22)$, respectively. 
Table 4B

Daily, Weekly, and Monthly S\&P500 HAR-RV-CJ Regressions

\begin{tabular}{|c|c|c|c|c|c|c|c|c|c|}
\hline \multicolumn{10}{|c|}{$\begin{array}{c}\left(R V_{t, t+h}\right)^{1 / 2}=\beta_{0}+\beta_{C D} C_{t}^{1 / 2}+\beta_{C W}\left(C_{t-5, t}\right)^{1 / 2}+\beta_{C M}\left(C_{t-22, t}\right)^{1 / 2}+\beta_{J D} J_{t}^{1 / 2}+\beta_{J W}\left(J_{t-5, t}\right)^{1 / 2}+\beta_{J M} \\
\log \left(R V_{t, t+h}\right)=\beta_{0}+\beta_{C D} \log \left(C_{t}\right)+\beta_{C W} \log \left(C_{t-5, t}\right)+\beta_{C M} \log \left(C_{t-22, t}\right)+ \\
\beta_{J D} \log \left(J_{t}+1\right)+\beta_{J W} \log \left(J_{t-5, t}+1\right)+\beta_{J M} \log \left(C_{t-22, t}+1\right)+\epsilon_{t, t+h}\end{array}$} \\
\hline \multirow[b]{2}{*}{$h$} & \multicolumn{3}{|c|}{$R V_{t, t+h}$} & \multicolumn{3}{|c|}{$\left(R V_{t, t+h}\right)^{1 / 2}$} & \multicolumn{3}{|c|}{$\log \left(R V_{t, t+h}\right)$} \\
\hline & 1 & 5 & 22 & 1 & 5 & 22 & 1 & 5 & 22 \\
\hline $3_{0}$ & $\begin{array}{c}0.118 \\
(0.042)\end{array}$ & $\begin{array}{c}0.194 \\
(0.055)\end{array}$ & $\begin{array}{c}0.314 \\
(0.071)\end{array}$ & $\begin{array}{c}0.060 \\
(0.018)\end{array}$ & $\begin{array}{c}0.098 \\
(0.028)\end{array}$ & $\begin{array}{c}0.187 \\
(0.044)\end{array}$ & $\begin{array}{l}-0.081 \\
(0.014)\end{array}$ & $\begin{array}{c}0.000 \\
(0.020)\end{array}$ & $\begin{array}{c}0.039 \\
(0.039)\end{array}$ \\
\hline$C D$ & $\begin{array}{c}0.292 \\
(0.098)\end{array}$ & $\begin{array}{c}0.180 \\
(0.064)\end{array}$ & $\begin{array}{c}0.115 \\
(0.035)\end{array}$ & $\begin{array}{c}0.342 \\
(0.043)\end{array}$ & $\begin{array}{c}0.231 \\
(0.033)\end{array}$ & $\begin{array}{c}0.164 \\
(0.023)\end{array}$ & $\begin{array}{c}0.286 \\
(0.026)\end{array}$ & $\begin{array}{c}0.196 \\
(0.020)\end{array}$ & $\begin{array}{c}0.136 \\
(0.020)\end{array}$ \\
\hline $3_{C W}$ & $\begin{array}{c}0.500 \\
(0.144)\end{array}$ & $\begin{array}{c}0.487 \\
(0.145)\end{array}$ & $\begin{array}{c}0.214 \\
(0.078)\end{array}$ & $\begin{array}{c}0.370 \\
(0.067)\end{array}$ & $\begin{array}{c}0.418 \\
(0.077)\end{array}$ & $\begin{array}{c}0.238 \\
(0.061)\end{array}$ & $\begin{array}{c}0.374 \\
(0.042)\end{array}$ & $\begin{array}{c}0.379 \\
(0.051)\end{array}$ & $\begin{array}{c}0.236 \\
(0.047)\end{array}$ \\
\hline $3_{C M}$ & $\begin{array}{c}0.126 \\
(0.093)\end{array}$ & $\begin{array}{c}0.178 \\
(0.115)\end{array}$ & $\begin{array}{c}0.442 \\
(0.096)\end{array}$ & $\begin{array}{c}0.196 \\
(0.049)\end{array}$ & $\begin{array}{c}0.245 \\
(0.070)\end{array}$ & $\begin{array}{c}0.422 \\
(0.076)\end{array}$ & $\begin{array}{c}0.269 \\
(0.034)\end{array}$ & $\begin{array}{c}0.335 \\
(0.050)\end{array}$ & $\begin{array}{c}0.488 \\
(0.060)\end{array}$ \\
\hline$\beta_{J D}$ & $\begin{array}{l}-0.116 \\
(0.077)\end{array}$ & $\begin{array}{c}0.018 \\
(0.040)\end{array}$ & $\begin{array}{c}0.026 \\
(0.017)\end{array}$ & $\begin{array}{l}-0.007 \\
(0.052)\end{array}$ & $\begin{array}{c}0.018 \\
(0.030)\end{array}$ & $\begin{array}{c}0.032 \\
(0.017)\end{array}$ & $\begin{array}{c}0.021 \\
(0.070)\end{array}$ & $\begin{array}{c}0.013 \\
(0.045)\end{array}$ & $\begin{array}{c}0.039 \\
(0.031)\end{array}$ \\
\hline $3_{J W}$ & $\begin{array}{c}0.486 \\
(0.235)\end{array}$ & $\begin{array}{c}0.351 \\
(0.151)\end{array}$ & $\begin{array}{c}0.524 \\
(0.223)\end{array}$ & $\begin{array}{c}0.128 \\
(0.071)\end{array}$ & $\begin{array}{c}0.132 \\
(0.062)\end{array}$ & $\begin{array}{c}0.166 \\
(0.087)\end{array}$ & $\begin{array}{c}0.161 \\
(0.108)\end{array}$ & $\begin{array}{c}0.240 \\
(0.108)\end{array}$ & $\begin{array}{c}0.334 \\
(0.129)\end{array}$ \\
\hline$\beta_{J M}$ & $\begin{array}{c}0.308 \\
(0.341)\end{array}$ & $\begin{array}{c}0.309 \\
(0.422)\end{array}$ & $\begin{array}{l}-0.285 \\
(0.294)\end{array}$ & $\begin{array}{c}0.103 \\
(0.067)\end{array}$ & $\begin{array}{c}0.090 \\
(0.093)\end{array}$ & $\begin{array}{c}0.003 \\
(0.111)\end{array}$ & $\begin{array}{c}0.123 \\
(0.098)\end{array}$ & $\begin{array}{c}0.047 \\
(0.135)\end{array}$ & $\begin{array}{l}-0.145 \\
(0.146)\end{array}$ \\
\hline $\mathrm{R}^{2}{ }_{H A R-R V-C J}$ & 0.411 & 0.571 & 0.487 & 0.602 & 0.695 & 0.632 & 0.679 & 0.758 & 0.721 \\
\hline
\end{tabular}

Key: The table reports the OLS estimates for daily $(\mathrm{h}=1)$ and overlapping weekly $(\mathrm{h}=5)$ and monthly $(\mathrm{h}=22)$ HAR-RV-CJ volatility forecast regressions. All of the realized volatility measures are constructed from five-minute returns spanning the period from January 1990 through December 2002, for a total of 3,262 daily observations. The weekly and monthly measures are given by the scaled sum of the corresponding daily measures. The significant daily jump and continuous sample path variability measures are based on equations (19) and (20), respectively, using a critical value of $\alpha=0.999$. The standard errors reported in parentheses are based on a Newey-West/Bartlett correction allowing for serial correlation of up to order $5(\mathrm{~h}=1), 10(\mathrm{~h}=5)$ and $44(\mathrm{~h}=22)$, respectively. 
Table 4C

Daily, Weekly, and Monthly U.S. T-Bond HAR-RV-CJ Regressions

\begin{tabular}{|c|c|c|c|c|c|c|c|c|c|}
\hline \multicolumn{10}{|c|}{$\begin{array}{r}\left(R V_{t, t+h}\right)^{1 / 2}=\beta_{0}+\beta_{C D} C_{t}^{1 / 2}+\beta_{C W}\left(C_{t-5, t}\right)^{1 / 2}+\beta_{C M}\left(C_{t-22, t}\right)^{1 / 2}+\beta_{J D} J_{t}^{1 / 2}+\beta_{J W}\left(J_{t-5, t}\right)^{1 / 2}+\beta_{J M} \\
\log \left(R V_{t, t+h}\right)=\beta_{0}+\beta_{C D} \log \left(C_{t}\right)+\beta_{C W} \log \left(C_{t-5, t}\right)+\beta_{C M} \log \left(C_{t-22, t}\right)+ \\
\beta_{J D} \log \left(J_{t}+1\right)+\beta_{J W} \log \left(J_{t-5, t}+1\right)+\beta_{J M} \log \left(C_{t-22, t}+1\right)+\epsilon_{t, t+h}\end{array}$} \\
\hline & \multicolumn{3}{|c|}{$R V_{t, t+h}$} & \multicolumn{3}{|c|}{$\left(R V_{t, t+h}\right)^{1 / 2}$} & \multicolumn{3}{|c|}{$\log \left(R V_{t, t+h}\right)$} \\
\hline & 1 & 5 & 22 & 1 & 5 & 22 & 1 & 5 & 22 \\
\hline 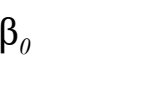 & $\begin{array}{c}0.084 \\
(0.011)\end{array}$ & $\begin{array}{c}0.093 \\
(0.012)\end{array}$ & $\begin{array}{c}0.132 \\
(0.016)\end{array}$ & $\begin{array}{c}0.134 \\
(0.016)\end{array}$ & $\begin{array}{c}0.163 \\
(0.019)\end{array}$ & $\begin{array}{c}0.235 \\
(0.029)\end{array}$ & $\begin{array}{l}-0.334 \\
(0.042)\end{array}$ & $\begin{array}{l}-0.318 \\
(0.052)\end{array}$ & $\begin{array}{l}-0.465 \\
(0.078)\end{array}$ \\
\hline & $\begin{array}{c}0.036 \\
(0.027)\end{array}$ & $\begin{array}{c}0.046 \\
(0.013)\end{array}$ & $\begin{array}{c}0.018 \\
(0.006)\end{array}$ & $\begin{array}{c}0.043 \\
(0.023)\end{array}$ & $\begin{array}{c}0.054 \\
(0.012)\end{array}$ & $\begin{array}{c}0.024 \\
(0.006)\end{array}$ & $\begin{array}{c}0.061 \\
(0.022)\end{array}$ & $\begin{array}{c}0.056 \\
(0.011)\end{array}$ & $\begin{array}{l}0.028 \\
(0.007)\end{array}$ \\
\hline & $\begin{array}{c}0.357 \\
(0.049)\end{array}$ & $\begin{array}{c}0.244 \\
(0.043)\end{array}$ & $\begin{array}{c}0.183 \\
(0.037)\end{array}$ & $\begin{array}{c}0.334 \\
(0.043)\end{array}$ & $\begin{array}{c}0.225 \\
(0.039)\end{array}$ & $\begin{array}{c}0.173 \\
(0.033)\end{array}$ & $\begin{array}{c}0.314 \\
(0.042)\end{array}$ & $\begin{array}{c}0.206 \\
(0.039)\end{array}$ & $\begin{array}{c}0.162 \\
(0.031)\end{array}$ \\
\hline & $\begin{array}{c}0.368 \\
(0.061)\end{array}$ & $\begin{array}{c}0.439 \\
(0.061)\end{array}$ & $\begin{array}{c}0.395 \\
(0.070)\end{array}$ & $\begin{array}{c}0.381 \\
(0.048)\end{array}$ & $\begin{array}{c}0.447 \\
(0.053)\end{array}$ & $\begin{array}{c}0.399 \\
(0.068)\end{array}$ & $\begin{array}{c}0.415 \\
(0.046)\end{array}$ & $\begin{array}{c}0.465 \\
(0.053)\end{array}$ & $\begin{array}{c}0.403 \\
(0.067)\end{array}$ \\
\hline$D$ & $\begin{array}{c}0.060 \\
(0.100)\end{array}$ & $\begin{array}{c}0.004 \\
(0.029)\end{array}$ & $\begin{array}{l}-0.006 \\
(0.011)\end{array}$ & $\begin{array}{c}0.019 \\
(0.036)\end{array}$ & $\begin{array}{c}0.010 \\
(0.014)\end{array}$ & $\begin{array}{c}0.005 \\
(0.008)\end{array}$ & $\begin{array}{l}-0.038 \\
(0.309)\end{array}$ & $\begin{array}{c}0.038 \\
(0.108)\end{array}$ & $\begin{array}{l}-0.014 \\
(0.052)\end{array}$ \\
\hline$J W$ & $\begin{array}{l}-0.042 \\
(0.164)\end{array}$ & $\begin{array}{l}-0.058 \\
(0.118)\end{array}$ & $\begin{array}{l}-0.039 \\
(0.093)\end{array}$ & $\begin{array}{c}0.035 \\
(0.039)\end{array}$ & $\begin{array}{c}0.025 \\
(0.034)\end{array}$ & $\begin{array}{c}0.019 \\
(0.028)\end{array}$ & $\begin{array}{c}0.165 \\
(0.518)\end{array}$ & $\begin{array}{l}-0.184 \\
(0.409)\end{array}$ & $\begin{array}{l}-0.228 \\
(0.343)\end{array}$ \\
\hline${ }_{J N}$ & $\begin{array}{l}-0.371 \\
(0.283)\end{array}$ & $\begin{array}{l}-0.345 \\
(0.329)\end{array}$ & $\begin{array}{l}-0.491 \\
(0.326)\end{array}$ & $\begin{array}{l}-0.174 \\
(0.055)\end{array}$ & $\begin{array}{l}-0.135 \\
(0.068)\end{array}$ & $\begin{array}{l}-0.140 \\
(0.080)\end{array}$ & $\begin{array}{l}-2.893 \\
(0.825)\end{array}$ & $\begin{array}{l}-1.399 \\
(1.044)\end{array}$ & $\begin{array}{l}-1.426 \\
(1.184)\end{array}$ \\
\hline $\mathrm{R}^{2}{ }_{H A R-R V-C J}$ & 0.130 & 0.317 & 0.369 & 0.177 & 0.346 & 0.389 & 0.206 & 0.359 & 0.397 \\
\hline
\end{tabular}

Key: The table reports the OLS estimates for daily $(\mathrm{h}=1)$ and overlapping weekly $(\mathrm{h}=5)$ and monthly $(h=22)$ HAR-RV-CJ volatility forecast regressions. All of the realized volatility measures are constructed from five-minute returns spanning the period from January 1990 through December 2002, for a total of 3,262 daily observations. The weekly and monthly measures are given by the scaled sum of the corresponding daily measures. The significant daily jump and continuous sample path variability measures are based on equations (19) and (20), respectively, using a critical value of $\alpha=0.999$. The standard errors reported in parentheses are based on a Newey-West/Bartlett correction allowing for serial correlation of up to order $5(\mathrm{~h}=1), 10(\mathrm{~h}=5)$ and $44(\mathrm{~h}=22)$, respectively. 
Figure 1A

Daily DM/\$ Realized Volatilities and Jumps
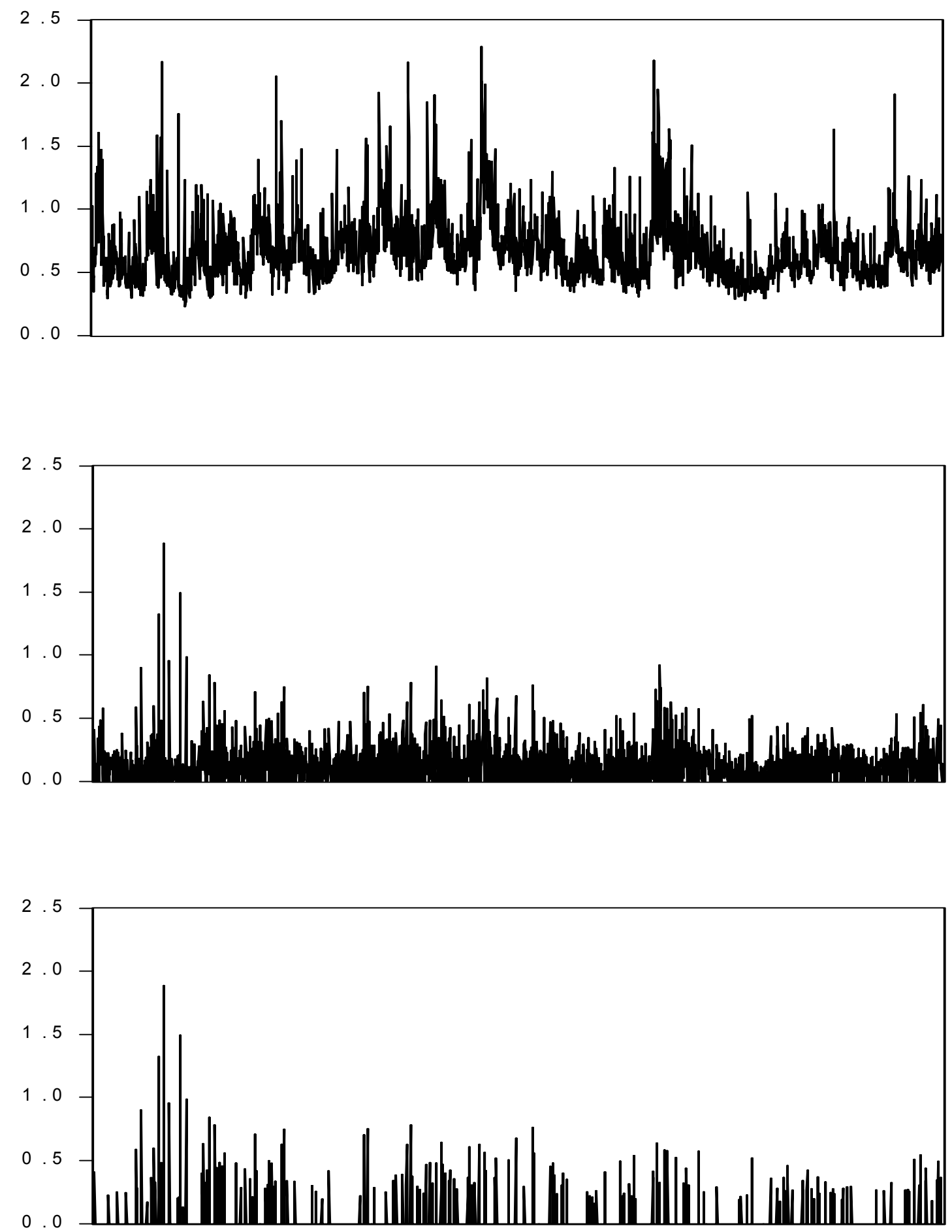

Key: The top panel shows daily realized volatility in standard deviation form, or $\mathrm{RV}_{\mathrm{t}}^{1 / 2}$. The middle panel shows the estimated jump component, and the bottom panel shows the "significant" jumps using a cutoff value of $\alpha=0.999$. See text for details and sample periods. 
Figure 1B

Daily S\&P500 Realized Volatilities and Jumps
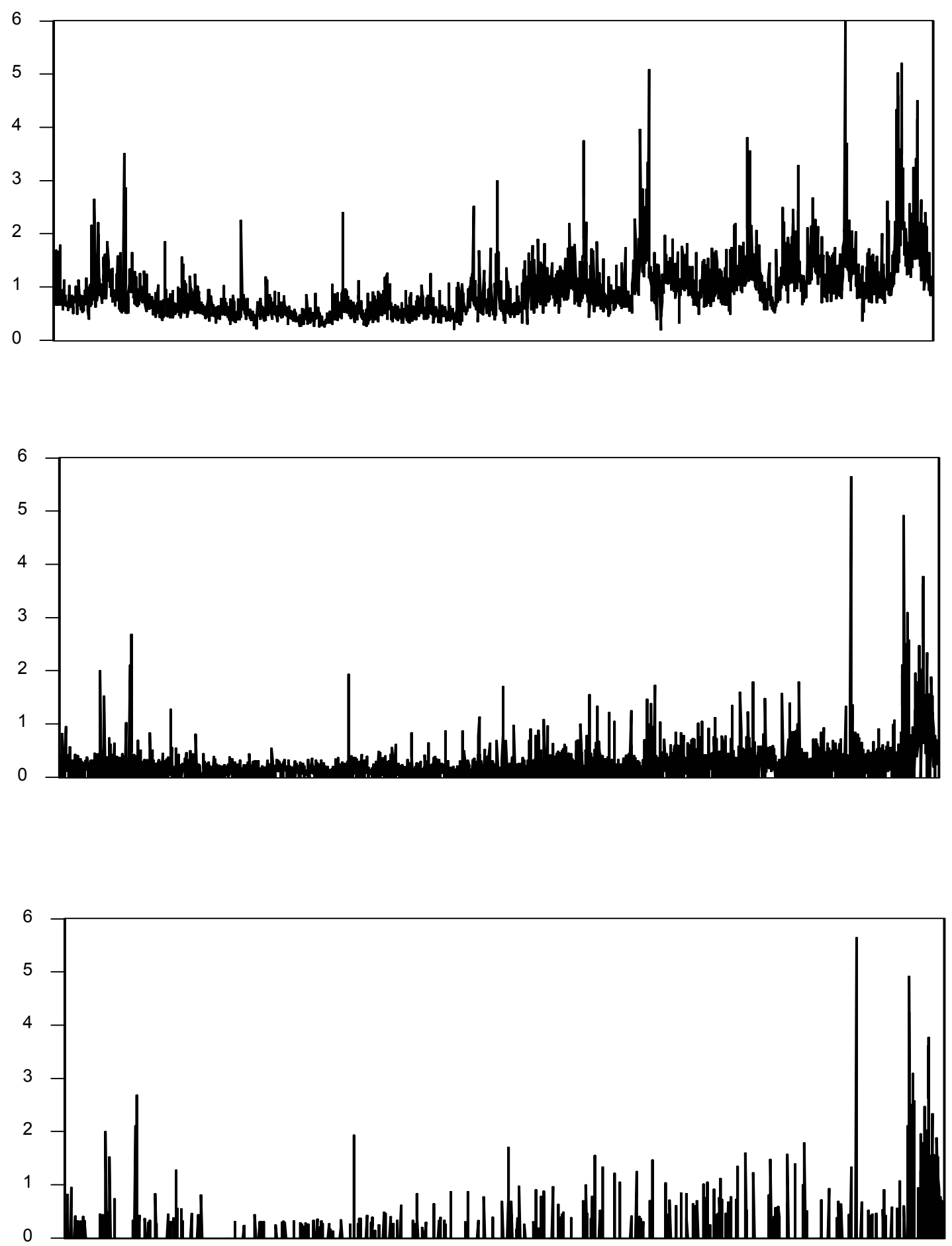

Key: The top panel shows daily realized volatility in standard deviation form, or $\mathrm{RV}_{\mathrm{t}}^{1 / 2}$. The middle panel shows the estimated jump component, and the bottom panel shows the "significant" jumps using a cutoff value of $\alpha=0.999$. See text for details and sample periods. 
Figure 1C

Daily U.S. T-Bond Realized Volatilities and Jumps
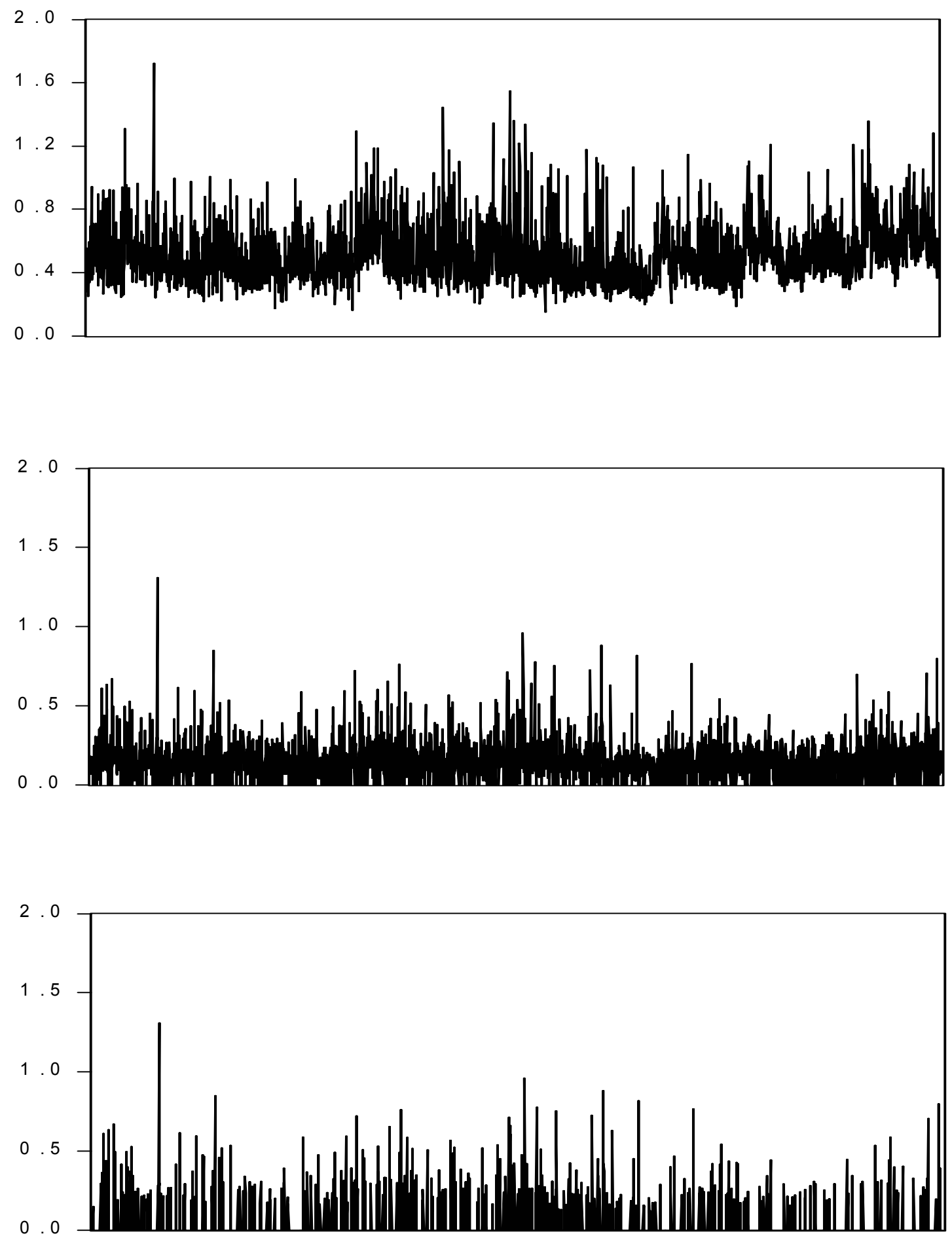

Key: The top panel shows daily realized volatility in standard deviation form, or $\mathrm{RV}_{\mathrm{t}}^{1 / 2}$. The middle panel shows the estimated jump component, and the bottom panel shows the "significant" jumps using a cutoff value of $\alpha=0.999$. See text for details and sample periods. 
Figure 2A

Daily, Weekly and Monthly HAR-RV-J DM/\$ Realized Volatility Forecasts
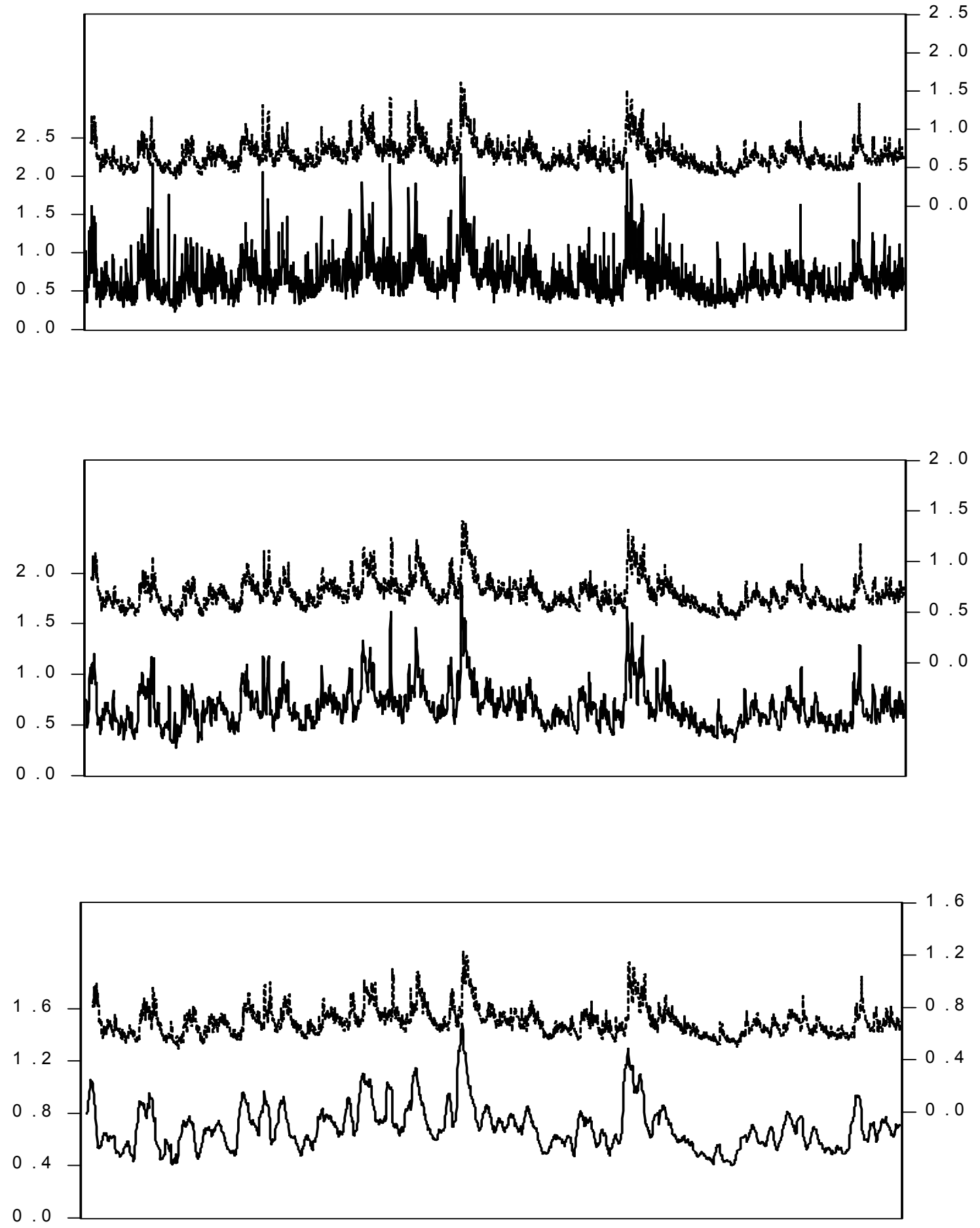

Key: The top, middle and bottom panels show daily, weekly and monthly realized volatilities (left scale) and forecasts (right scale). See text for details and sample periods. 
Figure 2B

Daily, Weekly and Monthly HAR-RV-J S\&P500 Realized Volatility Forecasts
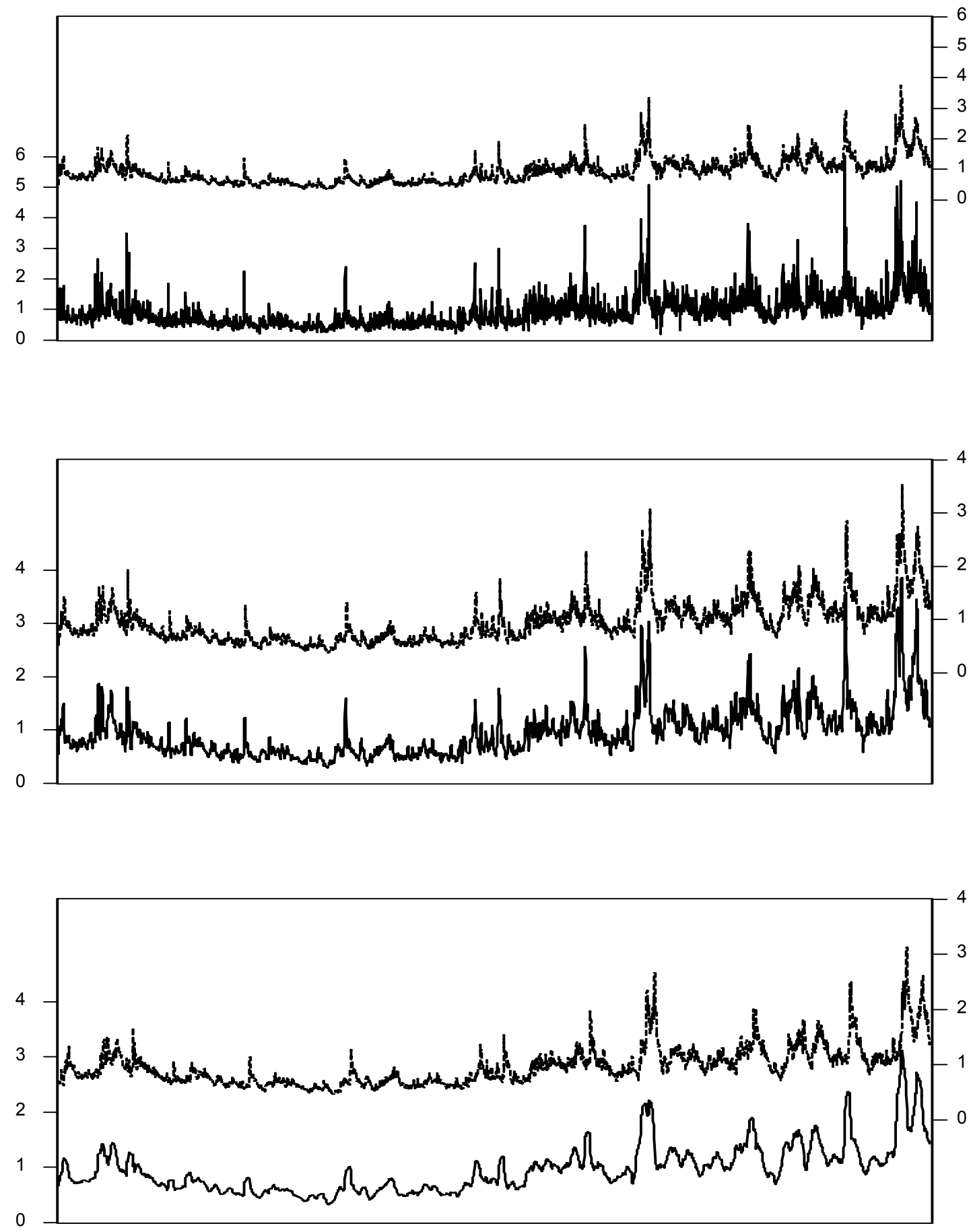

Key: The top, middle and bottom panels show daily, weekly and monthly realized volatilities (left scale) and forecasts (right scale). See text for details and sample periods. 
Figure 2C

Daily, Weekly and Monthly HAR-RV-J T-Bond Realized Volatility Forecasts
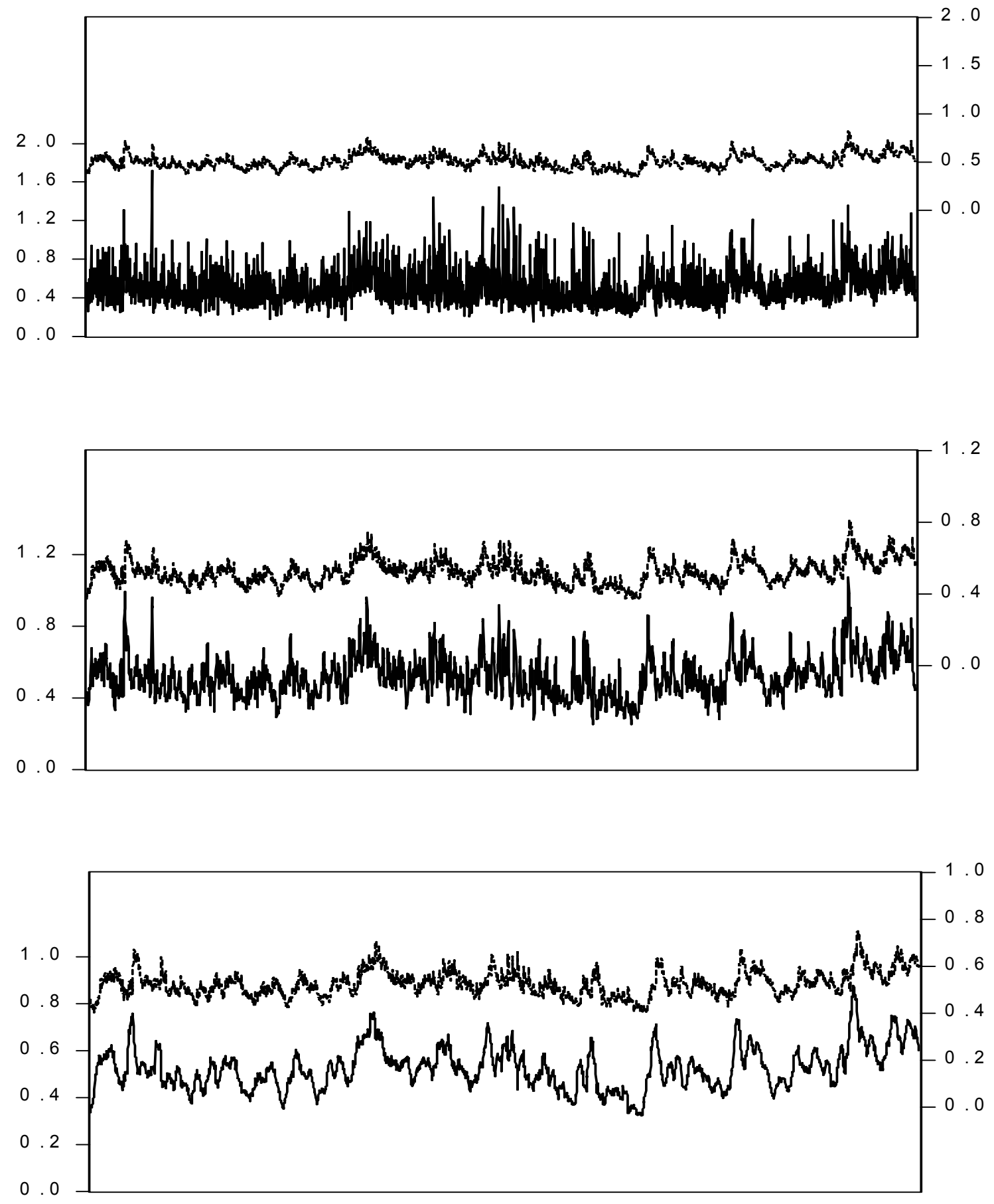

Key: The top, middle and bottom panels show daily, weekly and monthly realized volatilities (left scale) and forecasts (right scale). See text for details and sample periods. 